\title{
Behavior and gene expression in the brain of adult self-fertilizing mangrove rivulus fish (Kryptolebias marmoratus) after early life exposure to the neurotoxin $\beta$-N-methylamino-l-alanine (BMAA)
}

\author{
Alessandra Carion ${ }^{\mathrm{a}}$, Angèle Markey ${ }^{\mathrm{a}}$, Julie Hétrua ${ }^{\mathrm{a}}$, Camille Carpentier ${ }^{\mathrm{b}}$, VictoriaSuarez- \\ Ulloa $^{a}$, MathieuDenoël ${ }^{c}$, Ryan L.Earley ${ }^{d}$, FrédéricSilvestre ${ }^{a}$ \\ ${ }^{a}$ Laboratory of Evolutionary and Adaptive Physiology, Institute of Life, Earth and Environment, \\ University of Namur, 61 Rue de Bruxelles, 5000 Namur, Belgium \\ ${ }^{b}$ Research Unit of Environmental and Evolutionary Biology, Namur Institute of Complex Systems \\ (Naxys), and Institute of Life, Earth, and the Environment (ILEE), University of Namur, Rue de \\ Bruxelles 61, 5000 Namur, Belgium \\ ${ }^{c}$ Laboratory of Ecology and Conservation of Amphibians (LECA), Freshwater Oceanic Science \\ Unit of Research (FOCUS), University of Liège, 22 Quai van Beneden, 4020 Liège, Belgium \\ ${ }^{d}$ Department of Biological Sciences, University of Alabama, Tuscaloosa, AL 35487, USA
}

\section{Highlights}

- The goal of our study is to investigate the delayed effects of a neurotoxic compound and their underlying mechanisms.

- $\quad$ BMAA, a neurotoxin naturally produced by cyanobacteria, diatoms and dinoflagellates, constitutes a serious environmental and health threat.

- No delayed effects of BMAA on growth, reproduction, boldness and aggressiveness behavioral traits were observed.

- Change in relative expression of some genes in the brain indicates that BMAA might be excitotoxic.

- Our study revealed that BMAA can have long-lasting effects on the brain that are suspected to affect phenotypic traits with aging.

The present pdf is the author version. The final published pdf (i.e. with the layout of the publisher) is available in ORBi and in the publisher website (Elsevier - science Direct):

https://doi.org/10.1016/j.neuro.2020.04.007 


\begin{abstract}
$\beta$-N-Methylamino-l-alanine (BMAA), a neurotoxin naturally produced by cyanobacteria, diatoms and dinoflagellates, constitutes a serious environmental and health threat especially during acute blooms, which are becoming more frequent. This neurotoxin is implicated in several neurodegenerative diseases (ND) in humans through contaminated water or food consumption. Even low doses of neurotoxic compounds (NCs) can have lasting effects later in life. In this sense, early stages of development constitute a period of high sensitivity to environmental influence, particularly for the central nervous system. To understand the mechanisms underlying the delayed effects of NCs, newly hatched larvae of the mangrove rivulus fish, Kryptolebias marmoratus, were exposed to two sub-lethal doses of BMAA $(20 \mu \mathrm{g} / \mathrm{L}$ and $15 \mathrm{mg} / \mathrm{L})$ for 14 days. This fish naturally produces isogenic lineages due to its self-fertilizing reproduction, which is unique case among vertebrates. It thus provides genetic characteristics that allow scientists to study organisms' true reaction norm, minimizing genetic variability and focusing exclusively on the effects of the environment. Effect assessment was performed at different levels of biological organization to detect inconspicuous effects of BMAA, since this molecule displays long retention in organisms. BMAA effects on life history traits as well as behavioral traits such as boldness and aggressiveness were assessed more than 100 days after exposure. In addition, the relative expression of 7 potential BMAA target genes was studied, given their involvement in neurotransmission or their association with individual variation in boldness and aggressiveness. Selected genes code for reticulon 4 (RTN4), glutamate vesicular transporter 1 (Slc17a7), glutamine synthetase a (Glula), dopamine receptor D4 (DRD4), monoamine oxidase A (MAOA), calmodulin (CaM) and epedymine (Epd). Despite observing no effects of BMAA on growth, reproduction and behavioral traits, BMAA induced a significant increase of the expression of CaM and MAOA genes at $20 \mu \mathrm{g} / \mathrm{L}$ BMAA compared to the control group. A significant decrease of expression was observed between this lowest BMAA dose and $15 \mathrm{mg} / \mathrm{L}$ for DRD4, MAOA and CaM genes. Our results suggest disruption of glutamate turnover, intracellular dopamine depletion and activation of astrocyte protective mechanisms, indicating that BMAA might be excitotoxic. Our study revealed that BMAA can have long-lasting effects on the brain that are suspected to affect phenotypic traits with aging. Furthermore, it highlights the importance of studying delayed effects in ecotoxicological studies.
\end{abstract}

\title{
Keywords
}

BMAA, DOHaD, Neurotoxicity, Personality traits, Brain gene expression, Mangrove rivulus 


\section{Introduction}

$\beta$-N-Methylamino-l-alanine (BMAA) is a non-protein amino acid neurotoxicant produced by cyanobacteria, diatoms and dinoflagellates (Berntzon et al., 2015). BMAA has been detected in more than $90 \%$ of all studied cyanobacterial species suggesting widespread exposure (Cox et al., 2005). Increasing water eutrophication and phytoplankton bloom events, including some phytotoxin-producing species, make BMAA contamination a serious environmental and health issue (Faassen, 2014; O'Neil et al., 2012; Smith, 2003). This neurotoxicant has been the subject of multiple scientific studies during the last 50 years, and has been implicated in neurodegenerative diseases such as Guamanian amyotrophic lateral sclerosis/parkinsonism dementia complex (ALS/PDC), amyotrophic lateral sclerosis (ALS), Alzheimer's disease (AD), and Parkinson's disease (PD) (Chernoff et al., 2017; Chiu et al., 2011; Cox et al., 2018; Faassen, 2014; Lobner et al., 2007; Montine et al., 2005; Nunn, 2017; Rauk, 2018; Snyder et al., 2009). The origin of BMAA neurotoxicity comes from its excitotoxicity (van Onselen et al., 2018) (i.e., cell death resulting from the hyperactivity of excitatory amino acids (Chiu et al., 2011)). Briefly, BMAA reacts with bicarbonate ions to form $\beta$-carbamate, which can bind to glutamate receptors and inhibit the cysteine/glutamate antiport system (Xc- system) with consequences leading to increased Ca2+ influx, prolonged membrane depolarization, reactive oxygen species (ROS) production and activation of apoptotic mechanisms (Chiu et al., 2011; Purdie et al., 2009a; Rao et al., 2006; Chiu et al., 2011). BMAA also has a similar structure to alanine and serine and could thus be subjected to misincorporation during protein synthesis. The resulting protein aggregates have been implicated in neurodegenerative diseases (Glover et al., 2014; van Onselen et al., 2018). Moreover, BMAA is characterized as a "slow neurotoxin" due to its long latency between exposure and observation of the first symptoms. The origin of this delay would result in the existence of a "toxic tank" in which BMAA is associated with a protein, stored, and slowly excreted in a free form (Banack et al., 2005; Faassen, 2014; Rao et al., 2006). Recently, a clear link between BMAA exposure and neurodegeneration has been reported in neonatal rodents and non human primates displaying respectively behavioral and histopathological impairments in adulthood and neurological hallmarks of both Alzheimer's and Guamanian amyotrophic lateral sclerosis (Cox et al., 2016a, 2016b; Scott and Downing, 2019, 2017).

Early life stages (ELS) are particularly sensitive to neurotoxicants, even at low doses, due to the vulnerability of the central nervous system during development. Toxic exposure during ELS can damage the brain and potentially cause lasting effects that can be observed later in life (Aschengrau, 2016; Htway et al., 2019; Jedrychowski et al., 2015; Powers et al., 2017; Roen, 2015). It is therefore necessary to assess lasting BMAA effects on organisms exposed to sub-lethal doses during development to increase knowledge about mechanisms underlying delayed effects later in life (Barouki et al., 2018). Moreover, assessing effects at different biological endpoints 
(growth, fecundity, behaviors and gene expression) is imperative to avoid missing any hidden effects due to the particular characteristics of BMAA as a slow neurotoxin. To date, most studies have focused on humans and laboratory models such as rats and mice. Only a few studies have investigated the impacts of BMAA on other model organisms such as aquatic species (Frøyset et al., 2016; Karamyan and Speth, 2008; Powers et al., 2017; Purdie et al., 2009b). The present study aimed to assessing the effects of BMAA exposure during development on behavior and brain gene expression in the adult stage of an emerging model fish species, the mangrove rivulus, Kryptolebias marmoratus. This oviparous teleost fish belongs to the Rivulidae family and is native of mangrove habitats from the tropical and sub-tropical basins of the West Atlantic, ranging from Florida to coastal regions of Central America (Costa, 2011; Earley et al., 2012). This species is characterized by an androdioecious mixed-mating reproductive system. Populations consist mostly of hermaphrodites and by a small but variable proportion of males, where outcrossing is a more sporadic event than self-fertilization (selfing) (Kelley et al., 2016; Mackiewicz et al., 2006). Together with its sister species, $K$. hermaphroditus, the mangrove rivulus is the only known vertebrate capable of self-fertilization, and can produce highly homozygous and isogenic populations after a few generations without outcrossing (Costa, 2011; Harrington, 1961; Tatarenkov et al., 2009). These characteristics allow researchers to minimize genetic noise in scientific studies, and focus exclusively on how the environment influences the phenotype, ultimately defining "true reaction norms" (Earley et al., 2012; Kelley et al., 2016). Voisin and colleagues showed that early life exposure to an endocrine disrupting compound can induce delayed impacts on the adult phenotype and proteome (Voisin et al., 2016, 2018). A growing body of work on mangrove rivulus supports its value as a new model species optimally suited to investigate the potential lasting effects of environmental stressors and toxicant exposure. It is particularly well-suited for studying the role of epigenetic mechanisms in toxicity and ecotoxicity, as well as the role of epigenetics in ecology and evolution (Fellous et al., 2018). In addition to this species being of great interest for its capacity to selfing, rivulus is also subject to BMAA exposure in its natural environment since BMAA was found in resident species of South Florida as high as $7 \mathrm{mg} / \mathrm{g}$ of animal tissue (Brand et al., 2010). BMAA could therefore interfere with rivulus' behavior and neurobiological function, leading to detrimental consequences for population survival (Carion et al., 2018).

Organism's behaviors are extensively studied in ecotoxicology because the expression of behavior is highly sensitive to environmental stressors (Denoël et al., 2012). In fact, behavior integrates biochemical and physiological processes and reflects changes at higher levels of biological organization with ecological relevance (Hellou, 2011). This increasing interest in behavioral monitoring in xenobiotic studies stems from the fact that behavior is the ultimate output of an animal's nervous system. In order to survive, an organism has to be able to perform the right action at the right time, making behavior a major mechanism used by animals to acclimate and adapt to their environment (Brown and de Bivort, 2018; Sih et al., 2010). To adequately evaluate the impacts of a neurotoxicant on organisms' fitness, the study of personality traits such as boldness 
and aggressiveness becomes particularly relevant (Burns, 2008; Réale et al., 2007). The consistent between-individual differences in behavior over time and across contexts, also called personality traits or behavioral individualities, influence various parameters such as food access, social interactions, survival and, ultimately, the fitness of organisms (Réale et al., 2007; Stamps and Groothuis, 2010). The widespread existence of personalities across the animal kingdom suggests an evolutionary relevance. Although animals behavior constitutes the interactive link between an organism and its environment, behavioral individualities are largely interconnected with ecological dynamics and population evolution (Sih et al., 2010).

In a previous study, we showed that BMAA significantly affected the maximal speed and probability of successful prey capture in rivulus larvae exposed for 7 days immediately posthatching (Carion et al., 2018). Our objective in the present study is thus to assess whether BMAA exposure can affect more complex behaviors such as personality traits later in life. We hypothesize that BMAA exposure during early life can have lasting effects on molecular mechanisms that could impact gene expression, leading to disruptions in personality traits expression or changes in behavior. For that purpose, newly hatched larvae of mangrove rivulus were exposed directly after hatching to 2 sublethal doses of BMAA (low: $20 \mu \mathrm{g} / \mathrm{l}$ and high: $15 \mathrm{mg} / \mathrm{L}$ ) during 14 days in order to assess the delayed effects in adult fish personality traits (boldness and aggressiveness) and on the relative expression of 7 genes of interest. These doses were chosen according to a previous study assessing the immediate effects of 7 days BMAA exposure on locomotion and prey capture behavior of newly hatched larvae (Carion et al., 2018). The time of exposure was extended of 7 days compared to the previous study because the effects are assessed in adult fish more than 100 days after the exposure stopped. Boldness and aggressiveness were assessed in adults, more than 100 days after exposure stopped, while they are all young mature adults. Differences in relative expression of 7 genes implicated in boldness and aggressiveness behavioral traits and in neural signaling and metabolism were assessed in adult brains. Genes coding for glutamine synthetase a (Glula) and solute carrier family 17 member 7a (Slc17a7) were chosen as potential BMAA targets (Caller et al., 2018; Lewerenz and Maher, 2015; Popova et al., 2018). Genes coding for reticulon 4 protein (RTN4) (Pinzón-Olejua et al., 2014), ependymin (Epd) (Sneddon et al., 2011), D4 dopamine receptor (DRD4) (Garamszegi et al., 2014), calmodulin (CaM) (Sneddon et al., 2005) and monoamine oxidase A (MAOA) (Newman et al., 2005) were chosen for their potential roles in neurotransmission and/or personality traits.

\section{Materials and methods}

\subsection{Experimental fish and BMAA exposure}

Mangrove rivulus individuals used for this experiment are from the DC4 lineage currently housed at the University of Namur (Belgium) in $25 \pm 1$ parts per thousand (ppt) saltwater (Instant Ocean ${ }^{\mathrm{TM}}$ 
sea salt), at $25 \pm 1{ }^{\circ} \mathrm{C}, 12: 12$ light:dark cycle and fed every day ad libitum with living Artemia salina. As described in Voisin et al. (2016), this stock population was initially obtained from fish sampled by Ryan L. Earley and D. Scott Taylor in 2010 in the Florida Keys (Dove Creek; Tavernier, Florida; N25 $01^{\prime} 45.64^{\prime \prime}, \mathrm{W} 080^{\circ} 29^{\prime} 49.24$ '), and transferred to the University of Alabama (USA) to produce F1 and F2 generations via self-fertilization. F2 individuals were sent and acclimated to the housing facilities of the University of Namur.

Eggs used for the experiment were exclusively produced by hermaphrodite individuals. Hermaphrodites were raised individually in $500 \mathrm{~mL}$ capacity plastic container filled with $200 \mathrm{~mL}$ salt water. As they spawn at the air/water interface on cotton placed in their tank, eggs were collected on a daily basis and were individually placed in a plastic 24-wells microplates made for cell culture (Cellstar ${ }^{\circledR}$ ) filled with $25 \pm 1$ parts per thousand (ppt) saltwater (Instant Ocean ${ }^{\mathrm{TM}}$ sea salt) with one egg/well. Plates with eggs were kept in an incubator at $25 \pm 1{ }^{\circ} \mathrm{C}, 12: 12$ light:dark cycle and fed every day ad libitum with living Artemia salina. Water was changed every day until hatching. Larvae were then transferred in 6-wells microplates filled with salt water. BMAA treatments were randomly assigned directly after hatching on 0-day post-hatching (dph) autonomous larvae. Lyophilized $\beta$-N-methylamino-L-alanine hydrochloride (BMAA-HCl $50 \mathrm{mg}$ ) was purchased from Abraxis Inc. (Warminster, USA) and dissolved in $25 \pm 1$ ppt saltwater (Instant Ocean ${ }^{\mathrm{TM}}$ sea salt) to reach a final concentration of $382 \mathrm{mg} / \mathrm{L} \mathrm{BMAA}$ constituting the stock solution. A total of 159 newly hatched larvae were split into three groups and individually exposed to nominal sublethal BMAA concentrations of $20 \mu \mathrm{g} / \mathrm{L}, 15 \mathrm{mg} / \mathrm{L}$, or $0 \mathrm{mg} / \mathrm{L}$ (control) for 14 days in a volume of $6 \mathrm{~mL}$ (Table 1). These two BMAA doses were chosen according to Carion et al. (2018). They observed effects of 7-days BMAA exposure on rivulus larvae maximal speed at the environmentally relevant concentration $(20 \mu \mathrm{g} / \mathrm{L})$ and on their prey capture capabilities at both low and high concentrations. During the exposure period, $4 \mathrm{~mL}$ out of total $6 \mathrm{~mL}$ were renewed daily according to OECD \#210 guidelines (2013). At $7 \mathrm{dph}$, a complete water renewal was conducted. After the $14 \mathrm{dph}$ exposure, animals were individually transferred into a «cleaning bath » filled with salt water $\left(25 \pm 1 \mathrm{ppt}\right.$ at $\left.25 \pm 1^{\circ} \mathrm{C}\right)$. This manipulation was applied twice on each single fish to remove any trace of BMAA from fish skin. A cleaning bath was dedicated to control fish to avoid BMAA contamination and to apply the same manipulations. Then, each animal was individually transferred to a $500 \mathrm{~mL}$ plastic container filled with $200 \mathrm{~mL}$ of water and placed under the same physico-chemical conditions than stock fish. Larvae were fed every day ad libitum during exposure with living Artemia salina. 
Table 1. Total number of larvae raised per treatment, death, reproductively mature hermaphrodites, reproductively immature hermaphrodites, males and sample sizes used for growth monitoring, behavioral analyses and gene expression analyses. Males and immature hermaphrodites were excluded from behavioral analyses.

\begin{tabular}{ccccccccc}
\hline Treatments Larvae Death & $\begin{array}{c}\text { Mature } \\
\text { hermaphrodites }\end{array}$ & $\begin{array}{c}\text { Immature } \\
\text { hermaphrodites }\end{array}$ & Males Growth Behavior $\begin{array}{c}\text { Gene } \\
\text { expression }\end{array}$ \\
\hline Control & 50 & 0 & 45 & 1 & 4 & 30 & 45 & 8 \\
$\mathbf{2 0} \boldsymbol{\mu g} / \mathbf{L}$ & 51 & 1 & 48 & 1 & 1 & 33 & 48 & 9 \\
$\mathbf{1 5} \mathbf{~ m g / L}$ & 52 & 0 & 48 & 3 & 1 & 32 & 48 & 10 \\
\hline
\end{tabular}

All rivulus husbandry and experimental procedures were performed in accordance with the Belgian animal protection standards and were approved by the University of Namur Local Research Ethics Committee (UN $18318 \mathrm{KE}$ ). The agreement number of the laboratory for fish experiments is the LA1900048.

\subsection{Measurement of BMAA concentration by ELISA}

During the exposure period, $1 \mathrm{~mL}$ of water from each treated group was sampled and stored at $-20{ }^{\circ} \mathrm{C}$ to further assess the actual BMAA content of the water. BMAA concentration was measured using an ELISA kit developed by Abraxis (\#PN520040, Warminster, USA). Each sample was diluted to limit interference by salt from the water (at least 7-fold dilution for $25 \mathrm{ppt}$ saltwater) and to obtain an approximate concentration of $100 \mu \mathrm{g} / \mathrm{L}$ BMAA (according to the manufacturers' user guide). Stock and $15 \mathrm{mg} / \mathrm{L}$ BMAA solutions were diluted accordingly and control water samples were diluted 10 times and used as blank. After adequate dilution to limit salt interference with ELISA kit, the $20 \mu \mathrm{g} / \mathrm{L}$ solution was not quantified because it was below kit quantification limit $(4 \mu \mathrm{g} / \mathrm{L})$.

\subsection{Monitoring of life history traits}

Fish growth and reproduction were monitored to assess potential effects of BMAA exposure on life history traits (Table 1). Larvae standard length (i.e., from tip of nose to posterior margin of the caudal peduncle) was quantified at 7 and 14 dph with a Nikon binocular SM21270 associated with NIS-elements software. At 30, 50, 80 and $170 \mathrm{dph}$, standard length from 35 random individuals per group was recorded through picture analysis on Image ${ }^{\mathrm{TM}}$ software. Each individual tank was checked for eggs twice per week for 10 weeks from 70 dph to 120 dph (maturity is achieved between 80 and $100 \mathrm{dph}$ in this species (Cole and Noakes, 1997)) to assess the age at first 
reproduction and fecundity (i.e., number of eggs produced). Proportion of males, reproducing hermaphrodites and non-reproducing hermaphrodites was calculated. After sexual maturity, males and hermaphrodites are easily distinguishable according to external characteristics. Males exhibit orange color, faded ocellus, and black margins on anal/caudal fins, while hermaphrodites are silver with a black ocellus on their caudal fins (Scarsella et al., 2018; Soto and Noakes, 1994). Distinction between males and hermaphrodites was confirmed by gonad dissection at $170 \mathrm{dph}$. Determination between reproductively mature and immature hermaphrodites was based on their egg production. Fish were considered reproductively immature hermaphrodites when no eggs were laid before $170 \mathrm{dph}$.

Data normality was assessed with Agostino \& Pearson test. Depending on the data distribution, differences among treatments in fish standard length were tested at each time point with a oneway analysis of variance (ANOVA) or a non-parametric Kruskal-Wallis test followed by Tukey's/Dunn's multiple comparisons test. Chi square test was used to assess differences in the proportion of males and hermaphrodites among treatments. Friedman test was applied on egg production data to test treatment differences in fecundity. Finally, survival curves were fitted using the cumulative percentage of mature individuals against age with the Kaplan-Meier method and curves were compared with the logRank and the Gehan-Breslow-Wilcoxon tests. Statistical analyses were performed using GraphPad Prism7TM.

\subsection{Behavioral tests}

Boldness and aggressiveness were recorded on adult hermaphrodites (Table 1) to assess potential delayed neurotoxic effects. Fish were tested at $120 \mathrm{dph}$ (106 days after exposure stopped) with the shelter test (Fig. S1-A) (also known as emergence test (Burns, 2008; Garcia et al., 2016)) followed $24 \mathrm{~h}$ later by a model test (Fig. S1-B) to assess fish boldness and aggressiveness, respectively. At $120 \mathrm{dph}$, fish are sexually mature. This two tests pattern was replicated at $134 \mathrm{dph}$ and $148 \mathrm{dph}$. Shelter test arenas consisted of a grey shelter giving access to a $21 \mathrm{~cm}$ diameter white, round open field filled with $1.4 \mathrm{~L}$ of saltwater $(25 \mathrm{ppt})\left(5.5 \mathrm{~cm}\right.$ of water depth) at $25 \pm 1{ }^{\circ} \mathrm{C}$. The focal fish was placed in the arena for 10 min of acclimation in the shelter covered with a dark grey lid and closed from the open field. After acclimation, the door between shelter and open field was lifted and each trial was video-recorded for $30 \mathrm{~min}$ ( 60 frames/s HDR-CX625 Sony camera) for further behavioral analyses of latency to exit shelter, total distance moved and total time spent inside the shelter. Model test arenas were rectangular white plastic containers $(25 \times 15 \mathrm{~cm})$ filled with $1 \mathrm{~L}$ saltwater (25 ppt, $4 \mathrm{~cm}$ of water depth) at $25 \pm 1{ }^{\circ} \mathrm{C}$. A dummy was placed in the left side of the rectangular arena with the head oriented towards the right side of the arena and the body positioned with a $30^{\circ}$ angle from the median line of the rectangular base of the tank. This dummy was a 3D-printed plastic model of mangrove rivulus crafted by Ryan L. Earley (University of Alabama, USA) and 
painted at the University of Namur with acrylic paints. Epoxy resin topcoat covered the model to isolate paint from water during behavioral tests. The dummy was attached with a rigid nylon wire on an epoxy resin base at $1 \mathrm{~cm}$ from the water surface. To stimulate aggressive behavior, the dummy size used for each rivulus tested was chosen among dummy sizes available (1.9, 2.4, 2.8 and $3.4 \mathrm{~cm}$ ) to be the closest from the mean standard body length of 10 random individuals at the three testing time points (Barlow et al., 1984; Earley et al., 2000). After acclimation for 5 min inside a white plastic cylinder, fish aggressive behaviors (latency to first bite and attack posture and total number of bites and attack posture) were video-recorded for $10 \mathrm{~min}$ (60 frames/s HDRCX625 Sony camera). The model test was chosen to measure rivulus aggressiveness because it is known to elicit less strength in the aggressive response of the focal fish compared to the mirror or the standard opponent tests (Earley et al., 2000). With the model test, the focal fish response does not depend on the image/real opponent display and therefore limits variability in the results.

Videos were analyzed by video-tracking using NoldusEthovision XT 13TM. This software converts automatically the fish images into pixels and therefore allows to quantify accurately movement patterns (Denoël et al., 2013). Manual scoring was used to record the number of bites and attack postures displayed by fish during the model test.

Correlations between boldness and aggressiveness variables were assessed with non-parametric Spearman test (rcorr function - Hmisc R package). Principal Component Analysis (PCA) was performed on shelter and model test results using R Studio ("dudi.pca" function from "ade4" R package - version: 0.99.903). Scores for boldness and aggressiveness levels were obtained using coordinates of each fish on PCA axis 1 and 2, respectively. Logit transformation was applied on aggressiveness scores to meet normality assumptions. Linear mixed models (LMMs) were used on boldness scores and aggressiveness scores using "lmer" function from "Ime4" R package: treatments and fish age were entered as fixed effects and individuals as random effects. No interaction between age and individuals was taken into account because we assume that boldness and aggressiveness are traits and, therefore, consistent across time. Nested model selection was based on the logLikelihood-ratio test. Repeatability was calculated for both models using "rpt" function from "rptR" package (Biro and Stamps, 2015). The repeatability computed was the enhanced consistency repeatability $\left(\sigma^{2}\right.$ individual $/ \sigma^{2}$ total $)$. It takes into account the variability due to treatments and fish age (fixed effects) and assumes that behaviors are changing the same way across time, a constraint due to the limited number of behavioral test repetitions across time in our experimental design (only 3 time points).

The effects of BMAA on behavioral tests across time (slope of score-fish age) were tested to determine whether acclimation/habituation occurred (Biro, 2012). Because each individual showed different pattern of behavior across time, we divided our timeline into two sequences and 
computed the difference between $120 \mathrm{dph}$ and $134 \mathrm{dph}$ scores and the difference between $134 \mathrm{dph}$ and $148 \mathrm{dph}$ scores. After testing model assumptions, LMMs were conducted on these data for both behavioral tests, and the models included treatment, fish age, and the treatment $\mathrm{x}$ fish age interaction as fixed effects.

\subsection{Brain collection}

Fish were immersed in $4{ }^{\circ} \mathrm{C}$ water at $170 \mathrm{dph}$ for euthanasia. Fish body was weighed and standard length recorded. Death was ensured by decapitation. The brain was removed, snap-frozen in liquid nitrogen and stored at $-80{ }^{\circ} \mathrm{C}$ for subsequent molecular analyses.

\subsection{Reverse transcription quantitative PCR (RT-qPCR)}

Expression of several genes of interest was analyzed in adult brains to assess persistent BMAA effects at the molecular level. Genes coding for glutamine synthetase a (Glula) and solute carrier family 17 member 7a (Slc17a7) were chosen as potential BMAA targets (Caller et al., 2018; Lewerenz and Maher, 2015; Popova et al., 2018). Genes coding for reticulon 4 protein (RTN4) (Pinzón-Olejua et al., 2014), ependymin (Epd) (Sneddon et al., 2011), D4 dopamine receptor (DRD4) (Garamszegi et al., 2014), calmodulin (CaM) (Sneddon et al., 2005) and monoamine oxidase A (MAOA) (Newman et al., 2005) were chosen for their potential roles in neurotransmission and/or personality traits. Twelve brains from fish expressing the extreme behaviors ( 3 bold, 3 shy, 3 aggressive and 3 non-aggressive) were selected per treatment. RNA from a total of 36 brains was thus extracted with $500 \mu \mathrm{L}$ of TRI Reagent (ThermoFisher Scientific) and $50 \mu \mathrm{L}$ of 1-Bromo-3-chloropropane (BCP). After 10 min incubation at room temperature and centrifugation at $12,000 \mathrm{x}$ g for $15 \mathrm{~min}$ at $4{ }^{\circ} \mathrm{C}$, the aqueous layer containing RNA was removed and added to $250 \mu \mathrm{L}$ of isopronanol to precipitate RNA. Two washing steps were performed by substituting isopropanol by ethanol 75\%. The dried pellet was resuspended in RNase Free water. DNase treatment was performed with RQ1 RNase-Free DNase kit ${ }^{\circledR}$ (PROMEGA) before converting $500 \mathrm{ng}$ RNA into cDNA with the RevertAid RT Reverse Transcription kit (ThermoFisher Scientific). Samples were stored at $-20^{\circ} \mathrm{C}$.

Primers efficiencies were tested with the following dilutions 5-25-125-625-3125x on cDNA pool of samples made from the 3 treatments. $2.5 \mu \mathrm{L}$ of diluted cDNA was added to $2.5 \mu \mathrm{L}$ of primers mix and $5 \mu \mathrm{L}$ of SYBR green (Bio $\operatorname{Rad} \AA)$. Three technical replicates were established per dilution. SYBR green quantitative PCR was conducted on a StepOnePlus Real-Time PCR System ${ }^{\circledR}$ (Applied Biosystems) with 40 cycles $\left(95^{\circ} \mathrm{C}, 3 \mathrm{~s} ; 60^{\circ} \mathrm{C}, 30 \mathrm{~s}\right)$. A melting curve and an end-point 
agarose gel electrophoresis followed by SYBR safe (Thermo Fisher) staining were used to check for accurate amplification of the target amplicon. Primer efficiencies were calculated according to the MIQE guidelines (Bustin et al., 2009) and accepted between 90 and 110\%. Relative expression of the genes of interest (GOI) was normalized with expression of the housekeeping gene $\beta$-actin using the Pfaffl method (Hellemans et al., 2007). This gene was selected after testing its overall stability value and its intragroup and intergroup variation using the algorithm developed in the Excel $^{\mathrm{TM}}$ add-in NormFinder ${ }^{\mathrm{TM}}$. This gene showed the highest stability value $(0.056)$ and the lowest variation $(0.005,0.003,0.009$ for intragroup variation in control, $20 \mu \mathrm{g} / \mathrm{L}$ and $15 \mathrm{mg} / \mathrm{L}$, respectively) compared to $18 \mathrm{~S}$ RNA gene. Primer characteristics are available in supplementary data (Table S1).

Aberrant values were searched by the method of Robust Fit Outliers (Huber M-estimation to estimate center and spread). A total of 3 values were consequently removed from the analysis (1 for RTN4, 1 for DRD4 and 1 for Epd). Differences among treatments in relative gene expression were tested with a non-parametric Kruskal-Wallis test followed by the Wilcoxon test for each pair. Statistical analyses were performed using JMPTM version 15.

\section{Results}

\subsection{BMAA concentrations assessment}

The measured concentration of BMAA in the working solution (nominal concentration of $15 \mathrm{mg} / \mathrm{L}$ ) was $20.0 \pm 2.5 \mathrm{mg} / \mathrm{L}$ (mean $\pm \mathrm{SD}$ ), the average of 13 measurements across 14 days of exposure. The average measured concentration for the stock solution (nominal concentration of $382 \mathrm{mg} / \mathrm{L}$ ) was $543.0 \pm 43.5 \mathrm{mg} / \mathrm{L}$ (mean $\pm \mathrm{SD}$ ). Data of actual BMAA concentrations in fish water are available in supplementary data (Table S2 and Figure S2). Even if higher than expected, results confirmed that fish were consistently exposed to BMAA during the entire exposure period. Although the working solution of $20 \mu \mathrm{g} / \mathrm{L}$ BMAA was below the kit detection limit $(4 \mu \mathrm{g} / \mathrm{L})$ after 7-fold dilution to avoid salt interaction with ELISA kit, measured concentrations of the working solution indicate that the intended exposure concentrations were achieved.

\subsection{Life history traits}

14 days of exposure to BMAA did not impact fish growth. At $7 \mathrm{dph}$, fish exposed to $20 \mu \mathrm{g} / \mathrm{L}$ BMAA were about $3 \%$ heavier, and fish exposed to $15 \mathrm{mg} / \mathrm{L}$ were about $6 \%$ heavier than unexposed controls; neither of these differences was statistically significant. After exposure and before sexual maturity ( $50 \mathrm{dph}$ ), the standard lengths of exposed and unexposed fish differed by only $1 \%$. At $170 \mathrm{dph}$, the standard lengths of controls and fish exposed to $20 \mu \mathrm{g} / \mathrm{L}$ or $15 \mathrm{mg} / \mathrm{L}$ BMAA were virtually indistinguishable (Table 2). 
Table 2. Data monitoring of fish standard length $(\mathrm{mm})$ at different ages. Mean $\pm \mathrm{SEM}$. dph $=$ days post hatching.

\begin{tabular}{cccc}
\hline Age (dph) & Control & $\mathbf{2 0} \boldsymbol{\mu g} / \mathbf{L}$ BMAA & $\mathbf{1 5} \mathbf{~ m g} / \mathbf{L}$ BMAA \\
\hline $\mathbf{7}$ & $6.47 \pm 0.10$ & $6.67 \pm 0.88$ & $6.87 \pm 0.11$ \\
$\mathbf{1 4}$ & $8.55 \pm 0.13$ & $8.47 \pm 0.13$ & $8.88 \pm 0.14$ \\
$\mathbf{3 0}$ & $14.54 \pm 0.22$ & $14.17 \pm 0.20$ & $14.40 \pm 0.21$ \\
$\mathbf{5 0}$ & $18.55 \pm 0.16$ & $18.31 \pm 0.24$ & $18.30 \pm 0.22$ \\
$\mathbf{8 0}$ & $23.45 \pm 0.25$ & $23.01 \pm 0.30$ & $23.07 \pm 0.34$ \\
$\mathbf{1 7 0}$ & $26.29 \pm 0.17$ & $26.29 \pm 0.13$ & $26.40 \pm 0.18$ \\
\hline
\end{tabular}

There were no significant effects of BMAA on the age of sexual maturity, and there were no significant differences in the survival curves among treatments (Log-rank test; $d f=1, \chi 2=0.011$, $\mathrm{P}=0.91$ ). On average, fish treated with BMAA reproduced 4 days earlier than controls but this difference was not statistically significant (Table 3). There were no significant differences in sex ratio (hermaphrodite:male) among control and BMAA exposed groups. The number of reproductively mature versus immature hermaphrodites was not significantly impacted by BMAA exposure (Chi-square test; $\mathrm{df}=4, \chi 2=4.68, \mathrm{P}=0.32$ ) (Table 1 ). BMAA exposure did not impact fecundity, with mean egg production per week being very similar among treatments, including the controls (Table 4). Graphs depicting life history traits in the three treatments are available in the supplementary materials (Figs. S3-S5)

Table 3. Fish age at first egg production. Mean \pm SEM, data are expressed in days post hatching (dph).

\begin{tabular}{clc}
\hline Control & $\mathbf{2 0} \boldsymbol{\mu g} / \mathrm{L}$ BMAA & $\mathbf{1 5} \mathbf{~ m g} / \mathrm{L} \mathrm{BMAA}$ \\
$\mathbf{9 7} \pm \mathbf{2}$ & $93 \pm 2$ & $92 \pm 2$ \\
\hline
\end{tabular}

Table 4. Mean egg production per week recorded during 10 weeks, from 70 to $120 \mathrm{dph}$. Mean \pm SEM.

\begin{tabular}{clc}
\hline Control & $\mathbf{2 0} \boldsymbol{\mu g} / \mathrm{L}$ BMAA & $\mathbf{1 5} \mathbf{~ m g} / \mathrm{L}$ BMAA \\
$\mathbf{0 . 9 6} \pm \mathbf{0 . 1 3}$ & $0.92 \pm 0.104$ & $0.82 \pm 0.093$ \\
\hline
\end{tabular}




\subsection{Behavioral traits}

Principal component analysis (PCA) identified two major axes that explained a total of $66.48 \%$ of the behavioral variation, 35.53\% for axis 1 and 30.95\% for axis 2 (Fig. 1-A)(Table 5). The first axis mostly explained a continuum of aggressive behavior. Latency to first bite ("Bite latency") and to first express an attack posture ("Attack posture latency") against the dummy during the model test loaded positively on the first axis, while total number of bites ("Bites") and total number of attack postures ("Attack postures") loaded negatively on this axis. More aggressive individuals thus have lower scores for the first principal component axis than less aggressive individuals. The second axis represents a continuum of boldness, with latency to first exit the shelter ("Latency out shelter") and total time spent inside the shelter ("Shelter time") during the emergence test loading negatively on this axis. Total distance moved ("Distance") in the open field during the test loaded positively on the second axis. We thus observe a shy-bold continuum, with bolder animals having higher scores for the second principal component axis than shyer animals. While behavioral elements within a given test (e.g., aggression or emergence) were strongly correlated, there were no significant behavioral correlations across the two tests (Table S3).

Table 5. Principal component analysis (PCA): eigenvalues and percentage of explained inertia by each component.

\begin{tabular}{ccccc}
\hline \multicolumn{2}{c}{ Component Eigenvalue Cumulated eigenvalues } & Percentage of inertia & Cumulated percentage of inertia \\
$\mathbf{1}$ & 2.4873 & 2.4873 & 35.533 & 35.533 \\
$\mathbf{2}$ & 2.1665 & 4.6538 & 30.95 & 66.48 \\
\hline
\end{tabular}

Linear mixed models (LMMs) showed no BMAA effect on fish boldness or aggressiveness but significant changes in behavior with fish age (Table 6). This result also appears on the PCA scatter of the 154 individuals: the three treatment clusters superimposed (Fig. 1B) while individuals become bolder and less aggressive over time (Fig. 1C). Graphical representations of behavioral response variables across time and treatments are available on Fig. 2 for the model test and on Fig. 3 for the shelter test. From 120 dph to 148 dph there was a decrease of $66 \%, 69 \%$, and $73 \%$ in the latency to first exit the shelter (i.e., increased boldness) in controls, $20 \mu \mathrm{g} / \mathrm{L} \mathrm{BMAA}$, and $15 \mathrm{mg} / \mathrm{L}$ BMAA treatments, respectively (Fig. 3A). With respect to aggression, there was a decrease of $83 \%, 58 \%$, and $48 \%$ in the number of bites from 120 to $148 \mathrm{dph}$ of the control, $20 \mu \mathrm{g} / \mathrm{L}$ BMAA, and $15 \mathrm{mg} / \mathrm{L}$ BMAA treatments, respectively (Fig. 2A). Detailed behavioral test results are available in supplementary data (Tables S4 and S5). 


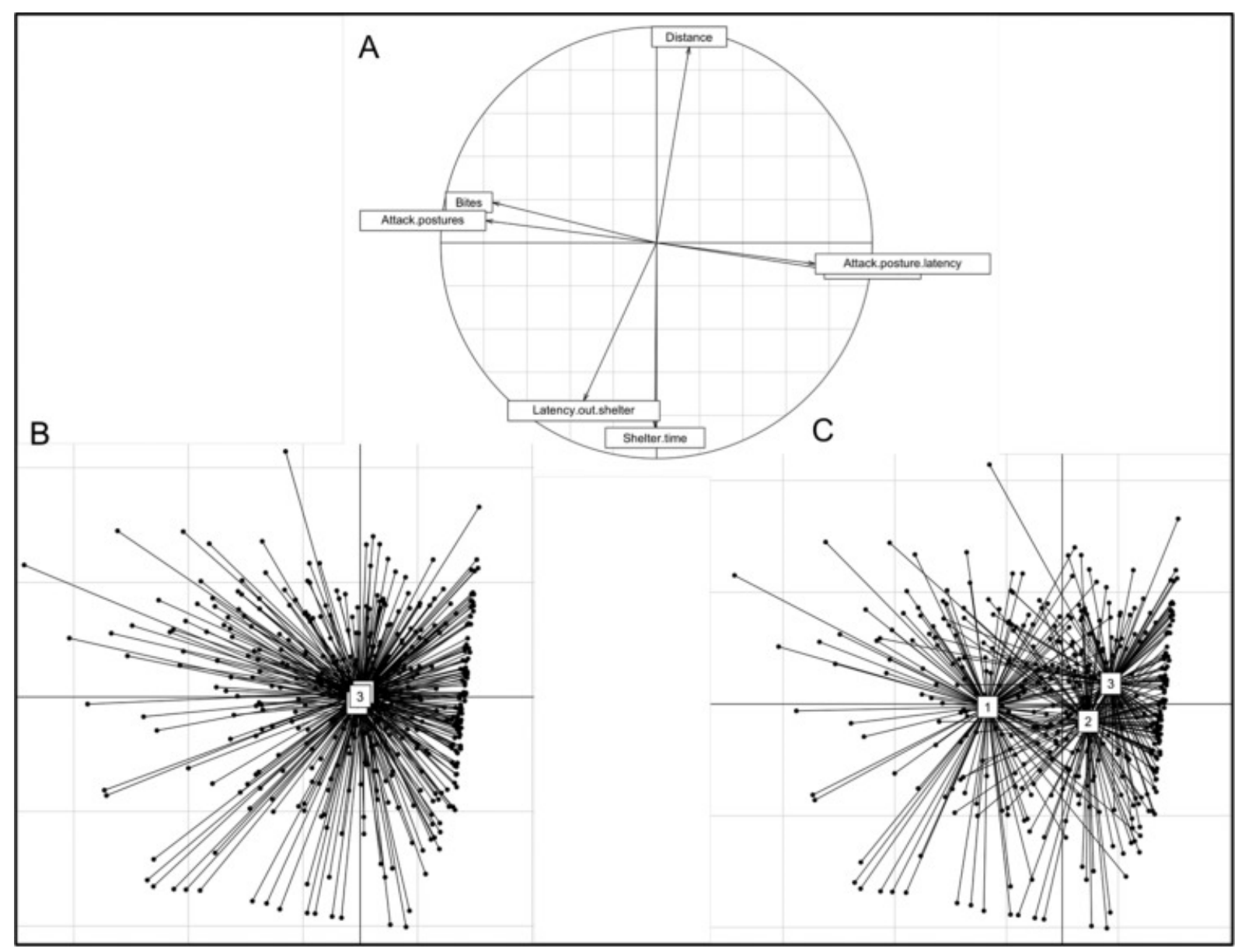

Fig. 1. Principal component analysis (PCA) on behavioral data obtained from the shelter and model tests on adult mangrove rivulus, Kryptolebias marmoratus, exposed to BMAA during development (A). Axis 1 (x-axis) corresponds to aggressive behavior, while axis 2 (y-axis) corresponds to boldness behavior. The orthogonal position of boldness and aggressiveness variables indicates the absence of correlation between these variables. Schematic representation of each individual for behavioral tests applied at 120, 134 and $148 \mathrm{dph}$ indicates (B) less effect of treatments on fish behaviors than (C) the effects of fish age.

There was significant among-individual variation in boldness (i.e., significant effect of 'individual'; $p=0.0393$; repeatability $[R]=0.104$ ) but not for aggression (Table 6 ).

LMMs applied on the change in behavior from $120 \mathrm{dph}$ to $134 \mathrm{dph}$, and from $134 \mathrm{dph}$ to $148 \mathrm{dph}$, assessed BMAA effects on fish response to behavioral tests across time (potential habituation/acclimation). There was no treatment effect and no interaction with fish age for boldness or aggressiveness scores (Table 7). 
Table 6. Linear mixed model results from PCA scores of shelter and model tests results.

\begin{tabular}{cccccccc}
\hline & \multicolumn{3}{c}{ Bold scores } & \multicolumn{3}{c}{ Aggressive scores } \\
\cline { 2 - 7 } Fixed effects & $\boldsymbol{F}$ & Dfn, Dfd & $\boldsymbol{p}$ & $\boldsymbol{F}$ & DFn, DFd & $\boldsymbol{p}$ \\
\hline Treatments & 0.5011 & 2,420 & 0.6059 & 0.8232 & 2,420 & 0.4529 \\
Fish age & 8.7918 & 2,420 & $\mathbf{0 . 0 0 0 2}$ & 115.0384 & 2,420 & $<\mathbf{0 . 0 0 0 1}$ \\
\hline Random effects & $F$ & Dfn, Dfd & $p$ & $F$ & Dfn, Dfd & $p$ \\
\hline Individuals & 4.2468 & 2,420 & 0.0393 & 1.6501 & 2,420 & 0.1989 \\
\hline Variance estimates & & & & & & \\
Among-individual variance & 0.2286 & & & 0.0819 & & \\
Within-individual variance (Residual) & 1.8807 & & & 1.1052 & & \\
\hline Enhanced consistency repeatability & $R$ & & & & & \\
\hline Random effects & $\mathbf{0 . 1 0 4 *}$ & & & & & & \\
\hline
\end{tabular}

Linear mixed model was applied on bold scores and aggressive scores with treatments and fish age as fixed factors and individuals as random factors. (Bold.score $\sim$ Treatment + Age + (1|Individual) ;(Nagg.score.logit $\sim$ Treatment + Age + (1|Individual). Total behavioral variation was partitioned into among- and within-individual variance. Repeatability estimates $(R)$ the proportion of trait variation that is attributed to among-individual differences. $R$ calculated is the enhanced « consistency repeatability » using rptR package. Bootstrapped $95 \%$ confidence intervals were computed from 1000 bootstraps to assess the signficance of $\mathrm{R}$ from 0 .

A

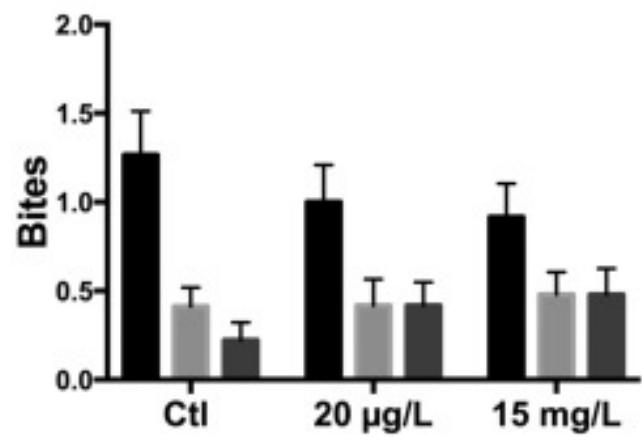

B

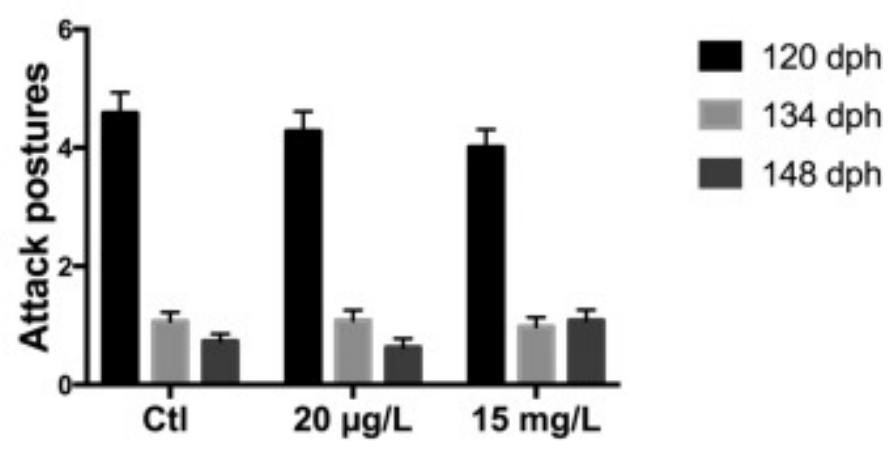

Fig. 2. Model test results recorded for the 3 treatments at 120, 134, and 148 days post hatching in mangrove rivulus. (A) Number of bites against the dummy, (B) number of attack postures against the dummy. Bar charts representing mean \pm SEM. 
A

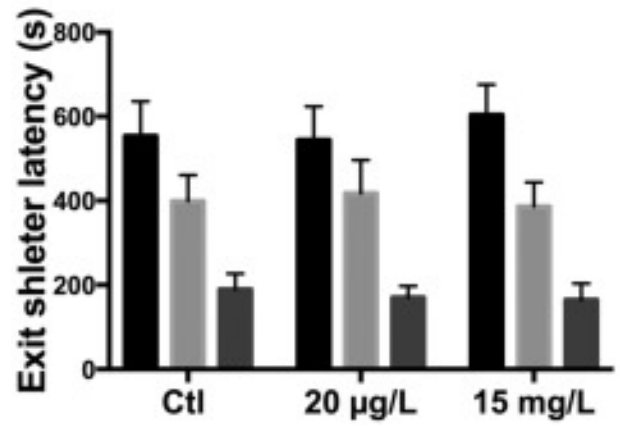

B

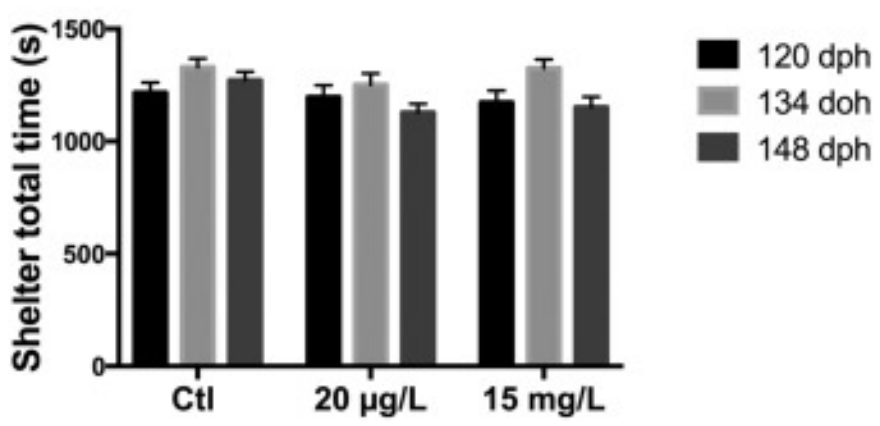

Fig. 3. Shelter test results recorded for the 3 treatments at 120,134, and 148 days post hatching in mangrove rivulus. (A) latency to exit shelter for the first time and (B) total time spent inside the shelter. Bar charts representing mean \pm SEM.

Table 7. Linear mixed model results of delta for shelter and model tests results.

\begin{tabular}{cccccccc}
\hline & \multicolumn{3}{c}{ Delta-Bold } & \multicolumn{3}{c}{ Delta-Aggressive } \\
Fixed effects & \multicolumn{1}{c}{ DFn, Dfd } & $\boldsymbol{p}$ & \multicolumn{1}{c}{$\boldsymbol{F}$} & \multicolumn{2}{c}{ DFn, Dfd } & $\boldsymbol{p}$ \\
\hline Treatments & 0.5277 & 2,420 & 0.5906 & 0.8936 & 2,420 & 0.4104 \\
Fish age & 16.6803 & 1,421 & $<\mathbf{0 . 0 0 0 1}$ & 48.5484 & 1,421 & $<\mathbf{0 . 0 0 0 1}$ \\
Treatment:Age & 0.0756 & 2,420 & 0.9272 & 0.077 & 2,420 & 0.9259 \\
\hline
\end{tabular}

Linear mixed model was applied on delta-bold and delta-aggressive with treatments and fish age as fixed and interacting factors. (Delta $\sim$ Treatment + Age + Treatment:Age).

\subsection{Relative gene expression}

Relative expression analyses in the brain revealed an overall trend for every gene of interest to be down-regulated in individuals exposed to the highest BMAA concentration $(15 \mathrm{mg} / \mathrm{L})$, except for Glula (Fig. 4). 


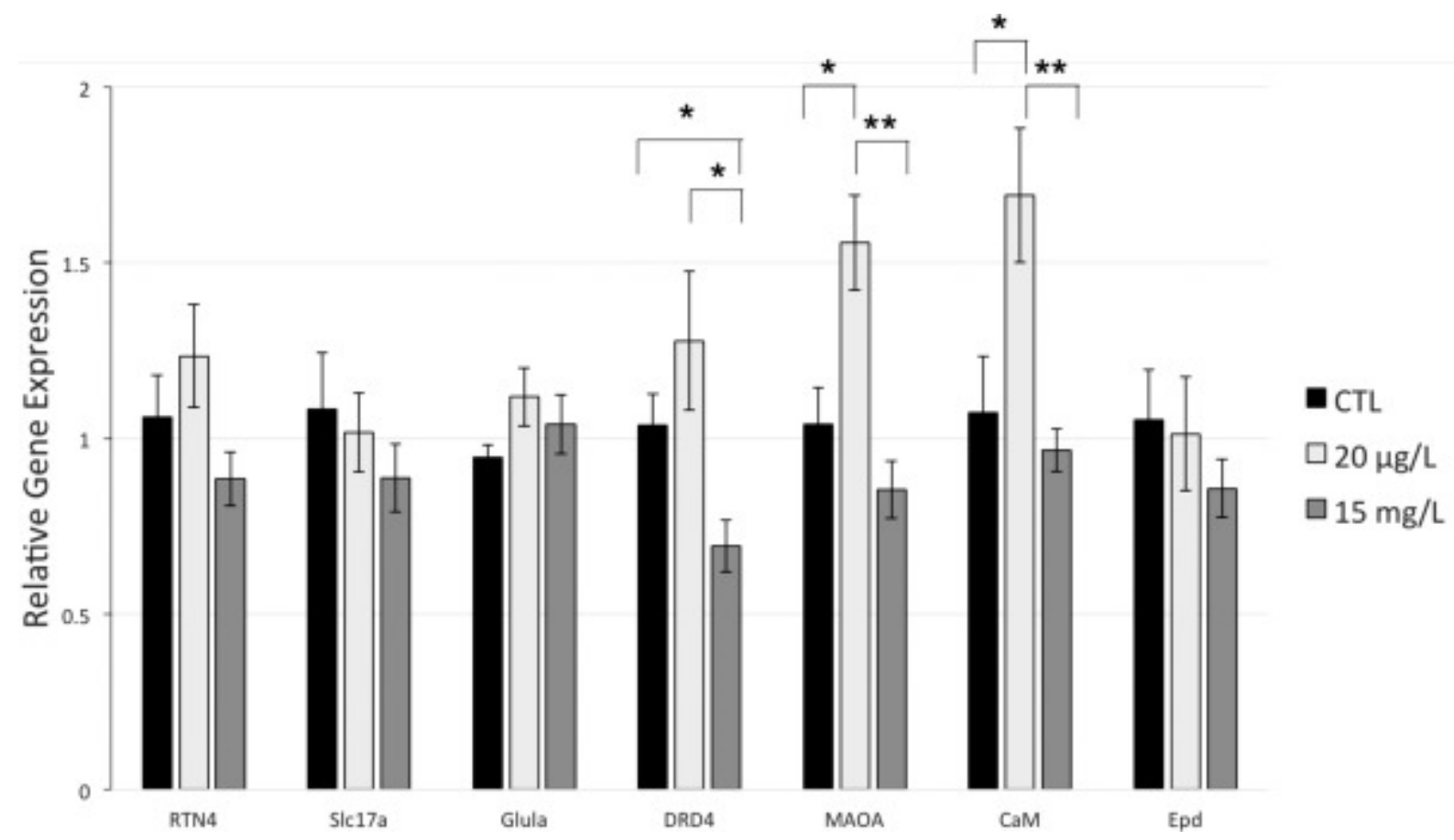

Fig. 4. Relative gene expression in the brain of adult Kryptolebias marmoratus in response to BMAA exposure $(0 \mu \mathrm{g} / \mathrm{L}, 20 \mu \mathrm{g} / \mathrm{L}$ and $15 \mathrm{mg} / \mathrm{L})$ during early life. Results are presented as mean $\pm \mathrm{SEM}$. Asterisks represent significantly different relative expression between groups. Reticulon 4 gene (RTN 4); Slc17a7 anionic receptor; Glutamine synthase a (Glula); Dopamine D4 receptor (DRD4); Monoamine oxidase A (MAOA); Calmodulin (CaM); and Ependymin (Epd) relative expression were measured. Housekeeping gene used is $\beta$-actin. Number of biological replicates used for $\mathrm{Ctl}=8$ except for Glula (7); $20 \mu \mathrm{g} / \mathrm{L} \mathrm{BMAA}=9$ except for RTN4 and Epd (8), and $15 \mathrm{mg} / \mathrm{L} \mathrm{BMAA}=10$ except for DRD4 (9). Significance levels (Wilcoxon test for each pair comparison) $* p<0.05$ (significant); ${ }^{* *} p<0.01$ (highly significant).

Significant increases of monoamine oxidase A (MAOA, $\mathrm{p}=0.0141)$ and calmodulin $(\mathrm{CaM}$, $\mathrm{p}=0.0304)$ relative expression occurred at low BMAA dose compared to controls.

Significant reduction of gene expression in fish brain exposed to $15 \mathrm{mg} / \mathrm{L}$ was observed for dopamine D4 receptor (DRD4; $\mathrm{p}=0.0171$ ), monoamine oxidase A (MAOA; $\mathrm{p}=0.0009$ ), and calmodulin $(\mathrm{CaM} ; \mathrm{p}=0.0048)$ compared to $20 \mu \mathrm{g} / \mathrm{L}$ exposed fish. A significant decrease of gene expression was observed in the $15 \mathrm{mg} / \mathrm{L}$ exposed fish compared to controls for DRD4 $(\mathrm{p}=0.0304)$. 


\section{Discussion}

Immediate effects of NCs can be observed on individuals directly after exposure, which consequently impairs behavior or other phenotypic traits (Carion et al., 2018; Mason et al., 2014). Our study aimed to determine the lasting and delayed effects of BMAA observed during later life, after exposure has ceased, in order to fully understand the long-term influence of neurotoxicant exposure. Exposure of mangrove rivulus larvae to BMAA indicated no effects on life history traits (growth, sexual maturity, fecundity and sex ratio). Even if a previous study had shown impairments on larvae mobility (increase of maximum velocity and prey capture failures), it appeared that BMAA exposure during early life did not impact boldness and aggressiveness in adult fish. However, we observed significant effects of BMAA on the relative expression of all 7 target genes, suggesting disruptions to glutamate turnover, intracellular dopamine depletion and astrocyte protective mechanisms. Our study revealed that BMAA might have long-lasting excitotoxic effects on the brain that are suspected to affect phenotypic traits with aging.

\subsection{BMAA effects on life history traits}

BMAA exposure had no notable effects on growth or reproduction, although fish exposed to BMAA reached sexual maturity (i.e., first egg production) 4 days earlier than controls. Growth is commonly used to assess chemical risk in ecotoxicological studies because size can influence reproductive success, vulnerability to predators, survival and ultimately fitness. Growth monitoring can thus furnish information about how chemicals affect populations and communities (Groh et al., 2015). BMAA has been shown to affect phytoplankton and zooplankton growth. Direct exposure to BMAA $(100 \mu \mathrm{g} / \mathrm{L})$ decreased somatic and population growth of Daphniamagna (Faassen et al., 2015). BMAA also reduced growth of diazotrophic cyanobacteria (Anebaena sp.) under conditions of nitrogen starvation (Popova et al., 2018). However, despite there being a significant body of research about neurotoxic chemicals, very little has been reported on their impacts on growth in vertebrates (Mason et al., 2014; Scott and Downing, 2017). Zebrafish embryos exposed to elevated concentrations $(\geq 10 \mathrm{pg} / \mathrm{egg})$ of azaspiracid-1 algae bloom toxin and mouse fetuses exposed to low doses of arsenic in their drinking water experienced reduced growth (Berry et al., 2007, Kozul-Horvath et al., 2012). However, mice exposed perinatally to BMAA $(50 \mathrm{mg} / \mathrm{kg} 3$ times a week - intranasally exposed from embryonic day 7-10 to postnatal days 21) did not show reduced somatic growth (Laugeray et al., 2018).

The primary regulator of vertebrate growth is the somatotropic axis, also known as the insulin-like growth factor1 (Igf1)/growth hormone (Gh) system (Dai et al., 2015). This axis is very informative 
of a broad range of stressful and growth-disturbing stimuli (Pérez-Sánchez et al., 2018). We previously showed that newly hatched mangrove rivulus larvae exposed to BMAA ( $20 \mu \mathrm{g} / \mathrm{L}$ and $15 \mathrm{mg} / \mathrm{L}$ ) for 7 days showed no effects on standard length (Carion et al., 2018). The present study confirmed those results, with no delayed effect of BMAA exposure on mangrove rivulus standard length, potentially indicating no interference of BMAA with growth regulators.

\subsection{BMAA effects on behavior}

We found no delayed effects of BMAA exposure on fish behavior, neither boldness nor aggressiveness. Numerous studies have implicated BMAA in the onset of neurodegenerative diseases (Chernoff et al., 2017; Chiu et al., 2011; Cox et al., 2018; Faassen, 2014; Lobner et al., 2007; Montine et al., 2005; Nunn, 2017; Rauk, 2018; Snyder et al., 2009). The study of behavior in the assessment of neurotoxicity of chemicals is widely used for years but very few studies have focused on the relationship between neurotoxicity and personality traits. We can report the response of mummichog, Fundulus heteroclitus, after the exposure to harmful algae toxins (brevetoxin, PbTx-2; and saxitonin, STX) that revealed significant alterations in schooling and shoaling behaviors with a decrease of social interaction with STX and an increase with PbTx-2. These two toxins generated higher frequency of solitary behaviors and altered startle (auditory/vibratory) and predator response (bird model) behaviors (Salierno, 2005). Perinatal exposure of mice to BMAA induces long lasting behavioral changes during the postnatal period and adulthood such as the appearance of some reflexes (negative geotaxis, righting reflex, bar grasping, and vertical progression) and communicative skills, changes in emotional cognition and abnormal sociability in females (Laugeray et al., 2018). They noticed that neuronal stem cells (NSCs) exposed to BMAA experienced higher ROS production and DNA damage. In contrast, a recent study measuring delayed BMAA effects on anxiety, locomotor activity, willingness to explore and memory of adult male mice failed to uncover any adverse cognitive effects (Myhre et al., 2018). Previous tests on adult mice fed with BMAA for 30 days also found no effects on motor coordination, motor neuron-mediated reflexes, locomotion, muscular strength or memory (CruzAguado et al., 2006). However, in a previous study, we showed significant effects of BMAA on the behavior of mangrove rivulus larvae immediately after 7 days of exposure, with an increase of $61 \%$ and $32 \%$ in maximum velocity during an open field test at $20 \mu \mathrm{g} / \mathrm{L}$ and $15 \mathrm{mg} / \mathrm{L} \mathrm{BMAA}$, respectively compared to control group. BMAA exposure also increased the number of failed prey capture attempts and the total trials necessary to catch a prey item (Carion et al., 2018). This previous study indicated that BMAA disrupts larvae locomotion and their ability to behave appropriately while hunting prey after 7 days of exposure. The present study indicates that BMAA mechanisms of action during early life exposure did not persist long enough to trigger phenotypic effects later in life in mangrove rivulus. 
BMAA induces diverse effects that vary with species, method and timing of exposure (CruzAguado et al., 2006; Karlsson et al., 2009b, 2009a). Neurotoxins can induce free radical generation (ROS) within neuronal cells, especially at the level of mitochondria. These harmful radicals oxidize macromolecules including lipids, proteins and DNA (Halliwell, 2007). If severe damage is sustained, it leads to apoptosis or necrosis of neurons and glia, which can interfere with proper central nervous system function and drive cognitive, sensory and motor deficits (Reiter et al., 2010). Protective mechanisms against free radicals coming from neurotoxin exposures exist in the brain, even if this organ is not especially effective in its antioxidant defensive system compared to its large production of ROS (Reiter et al., 2010; Salim, 2017). The absence of delayed effects on personality traits measured more than 100 days after developmental exposure of mangrove rivulus to BMAA could be due to the long latency between exposure and measurements. BMAA perturbations at the behavioral level might be reversible and unsubstantial. The delay between BMAA exposure and behavioral testing might have allowed time protective/repair mechanisms to operate. But we cannot reject the alternative hypothesis that behavioral traits were quantified too soon after exposure to BMAA, which tends to be retained for long periods and excreted at slow rates (Banack et al., 2005; Faassen, 2014; Rao et al., 2006).

\subsection{BMAA effects on relative gene expression}

In the present study, we could not report any significant differences in the expression of Reticulon 4 (RTN4), Slc17a7 encoding glutamate vesicular transporter 1 (VGLUT1), Glutamine synthetase a (Glula) and Ependymin (Epd) encoding genes between fish exposed to BMAA and fish that were unexposed. However, we reported two opposite effects of an early exposure of BMAA on gene expression in young adult fish. On the one hand, the highest tested dose of $15 \mathrm{mg} / \mathrm{L}$ BMAA significantly decreased the expression of Dopamine D4 receptor (DRD4) compared to the control group (-33\%) and to the lowest tested concentration group (-46\%) (Fig. 4).

BMAA effects on catecholamines (noradrenaline, dopamine, etc.) are poorly understood. However, excess of excitotoxicity-related intracellular calcium concentrations, which is a wellknown effect of BMAA (through activation of glutamate receptors), would induce prolonged cell depolarization, leading to membrane permeability that causes catecholamine intracellular depletion (Chiu et al., 2011). Similarly, Santiago et al. (2006) observed a dose-dependent increase in dopamine levels in extracellular medium of rat brains exposed to BMAA, possibly caused by increasing membrane permeability of neurons to catecholamines. This extracellular increase of catecholamine concentration can consequently overstimulate their receptors, which may negatively impact neural information processing (Horzmann and Freeman, 2016). The present observation of DRD4 gene down-regulation at the high BMAA dose might therefore be a compensatory, protective reaction to excitotoxicity related to dopamine abundance in the 
extracellular medium induced by BMAA exposure. However, further studies should measure the exact extracellular dopamine concentration before drawing conclusions.

On the other hand, exposure to $20 \mu \mathrm{g} / \mathrm{L}$ BMAA significantly increased the expression of the monoamine oxidase A (MAOA) $(+50 \%)$ and calmodulin $(\mathrm{CaM})(+58 \%)$ genes compared to the control group and to the high concentration group of $15 \mathrm{mg} / \mathrm{L}$ BMAA. MAOA is a key enzyme in the degradation process of biogenic amines such as serotonin and dopamine, which can lead to the synthesis of neuromelanin (Ziegler et al., 2016), a pigment mainly located in the catecholaminergic neurons (Haining and Achat-Mendes, 2017). The primary role of neuromelanin is to extract toxic metabolites that induce neurodegeneration (e.g., neurotoxic compounds) via its capacity to sequester iron, copper ions, and even BMAA (Zucca et al., 2014). The reported MAOA upregulation at low dose of BMAA may occur as a mechanism to reduce neurotoxicity by increasing production of intracellular neuromelanin. This hypothesis should be deepened by measuring the intracellular level of this pigment. It can be suggested here that a low dose of BMAA can stimulate MAOA expression in order to maintain normal neuronal activity, while the highest tested BMAA concentration was too high to induce this protection mechanism.

Under the same condition, BMAA exposure significantly increased CaM expression. Calmodulin, a major component of postsynaptic density complex (PSD), has a molecular structure that allows binding $4 \mathrm{Ca} 2+$ ions. When saturated, the modified structure interacts and activates a large number of target enzymes, which makes calmodulin a key protein in neurotransmission regulation (Carlin et al., 1981; Swulius and Waxham, 2008). Calmodulin kinase II (CaMKII) is one of calmodulin's major targets involved in synaptic plasticity and ion channel regulation. When activated by the $\mathrm{Ca} 2+/ \mathrm{CaM}$ complex, CaMKII activates glutamate receptors and increases their number by facilitating incorporation into the membrane (Swulius and Waxham, 2008). Studies have shown the involvement of CaMKII in excitotoxicity by glutamate. Viberg (2009) showed an increase in calcium/calmodulin-dependent protein kinase II in the hippocampus of rats exposed to a class of brominated flame retardants (polybrominated diphenyl ethers). There also was a decrease in excitotoxicity when glutamate injections were combined with CaMKII inhibition in mice (Ashpole and Hudmon, 2011). In addition, several studies have shown that CaMKII becomes inactive following an excitotoxic attack, preventing interaction with glutamate receptors (Ashpole et al., 2012; Churn et al., 1995). The observed increase of CaM expression level at the low BMAA concentration might indicate a role for CaMKII in elevating glutamate levels in the extracellular medium by stimulating glutamate receptor recruitment and subsequent excitotoxicity. This CaM expression increase could indicate that only higher BMAA concentrations activate protection mechanisms to limit neuronal damage. 
In our study, BMAA affected some gene expression with a trend of up-regulation and downregulation at low and high doses respectively reflecting excitotoxicity but also possible protective mechanisms. Four of the tested genes have been related to boldness or aggressiveness in some vertebrate species (DRD4, MAOA, CaM, Epd). Down-regulation in CaM expression has been associated with bold behavior in rainbow trout (Sneddon et al., 2005; Thomson et al., 2012), DRD4 with risk-taking behavior in a bird species (collared flycatcher) (Garamszegi et al., 2014), and MAOA with aggressive behavior in mice and rhesus monkeys (Cases et al., 1995; Newman et al., 2005). In the present study, the absence of effect on behavioral traits, despite changes in the expression of genes involved in those behaviors, could suggest that boldness and aggression are not affected by those genes in the mangrove rivulus, or that the observed range of expression changes is not high enough to trigger solid behavioral responses. An other possibility would be that these personality traits are more complex and underlain by a suite of genes having low effects, being globally unaffected by BMAA (Azuma et al., 2005).

In mangrove rivulus, gene expression analysis revealed that BMAA exposure during development could induce excitotoxicity and activation of protection mechanisms but, at the tested doses, did not lead to behavioral impairments later in life. It therefore remains possible that a potential link exists between the absence of delayed phenotypic effects and protective mechanisms afforded via regulation of gene expression. Moreover, because mangrove rivulus' lifespan in captivity is more or less 5 years (personal data) and has been reported to reach 8.2 years (Taylor, 2012), we cannot reject the hypothesis that altered patterns of gene expression might influence the behavioral phenotype in older fish, interfering with the aging process. In the present study, we assessed the effects of two weeks of BMAA exposure during early development, three months after exposure ceased. Fish were still in the first year of their life. However, neurodegenerative diseases tend to emerge about mid-way through life in human populations (Pagano et al., 2016). It is therefore possible that BMAA induces neurodegeneration later in life in mangrove rivulus impacting their behaviors, symptoms visible with aging such as the symptoms of Alzheimer disease appearing later in life (Isik, 2010; Yegambaram et al., 2015).

There is little data on free BMAA concentrations in natural aquatic systems but, the highest concentration recorded in Nebraska reservoirs was $25.3 \mu \mathrm{g} / \mathrm{L}$ in 2009 (Al-Sammak et al., 2014). In freshwater, considering concentrations of cyanobacterial cells in a bloom and the BMAA content reported in cyanobacteria, BMAA concentrations could potentially reach the $\mathrm{mg} / \mathrm{L}$ range (Esterhuizen-Londt and Downing, 2011). BMAA concentrations in free-living cyanobacteria was reported to vary with time of sampling, location, strains and water euthrophication from 0 to $6478 \mu \mathrm{g} / \mathrm{g}$ of dry weight in free form and from 0 to $5415 \mu \mathrm{g} / \mathrm{g}$ dry weight in protein-bound form (Cox et al., 2005). BMAA is also produced by diatoms and dinoflagellates and was reported to have bioaccumulation and biomagnification capacities (Lage et al., 2018). It is thus likely that elevated BMAA concentrations, such as the one tested in our experiment, exist during bloom 
events. However, the mangrove rivulus seems more resistant to this neurotoxin, at least in terms of its behavioral phenotype compared to another tropical fish species, the zebrafish, Danio rerio. In comparison, increased mortality, spinal axis deformations and seizures were observed in zebrafish larvae after 10 days of exposure to $5 \mu \mathrm{g} / \mathrm{L}$ BMAA in water (Purdie et al., 2009a) while no effects on life history traits, mortality or body mass were observed in our fish. Mangrove rivulus may have more efficient/plastic protective mechanisms that could come from its adaptation to harsh conditions of its natural environment including natural BMAA exposure compared to zebrafish (Brand et al., 2010).

\section{Conclusions}

In conclusion, we used a new vertebrate model species, the mangrove rivulus fish to assess delayed BMAA effect at different toxicology endpoints (life history traits, behavior and brain gene expression). The fact that this species is able to self-fertilize and to produce isogenic lineages permits explicit examination of environmental effects on the phenotype (i.e., construction of true reaction norms) by reducing the genetic "noise "in the experiment. We reported for the first time that BMAA exposure during early life can significantly impair gene expression in the brain of rivulus later in life. The absence of reported phenotypic effects does not mean that BMAA cannot be harmful for this species, but further studies should investigate the interaction with the aging process.

\section{Declaration of Competing Interest}

The authors declare that no competing interests exist.

\section{Acknowledgments}

This study was supported by the FRS-FNRS (Fonds de la Recherche Scientifique) PhD fellowship to A. Carion and a research grant number $N^{\circ}$ T.0174.14. M. Denoël is a Research Director at F.R.SFNRS.

\section{References}

Al-Sammak, M.A., Hoagland, K.D., Cassada, D., Snow, D.D., 2014. Co-occurrence of the cyanotoxins BMAA, DABA and anatoxin-a in Nebraska reservoirs, fish, and aquatic plants. Toxins (Basel). 6, 488-508. https://doi.org/10.3390/toxins6020488 
Aschengrau, A., 2016. Long-term neurotoxic effects of early life exposure to tetrachloroethylenecontaminated drinking water. Ann Glob Heal. 82, 169-179.

https://doi.org/10.1097/SLA.0000000000001177.Complications

Ashpole, N.M., Hudmon, A., 2011. Excitotoxic neuroprotection and vulnerability with CaMKII inhibition. Mol. Cell. Neurosci. 46, 720-730. https://doi.org/10.1016/J.MCN.2011.02.003

Ashpole, N.M., Song, W., Brustovetsky, T., Engleman, E.A., Brustovetsky, N., Cummins, T.R., Hudmon, A., 2012. Calcium/calmodulin-dependent protein kinase II (CaMKII) inhibition induces neurotoxicity via dysregulation of glutamate/calcium signaling and hyperexcitability. J. Biochem. chrmistry 287, 8495-8506. https://doi.org/10.1074/jbc.M111.323915

Azuma, T., Dijkstra, J.M., Kiryu, I., Sekiguchi, T., Terada, Y., Asahina, K., Fischer, U., Ototake, M., 2005. Growth and behavioral traits in donaldson rainbow trout (Oncorhynchus mykiss) cosegregate with classical major histocompatibility complex (MHC) class I genotype. Behav. Genet. 35, 463-478. https://doi.org/10.1007/s10519-004-0863-6

Banack, S.A., Cox, P.A., Perl, D.P., Galasko, D., 2005. Biomagnification of cycad neurotoxins in flying foxes: implications for ALS-PDC in Guam. Neurology 65, 387-9. https://doi.org/10.1212/01.wnl.0000174523.62022.52

Barlow, G., Rogers, W., Bond, A., 1984. Dummy-elicited aggressive behavior in the polychromatic midas cichlid. Biol. Behav. 9, 115-130.

Barouki, R., Melén, E., Herceg, Z., Beckers, J., Chen, J., Karagas, M., Puga, A., Xia, Y., Chadwick, L., Yan, W., Audouze, K., Slama, R., Heindel, J., Grandjean, P., Kawamoto, T., Nohara, K., 2018. Epigenetics as a mechanism linking developmental exposures to long-term toxicity. Environ. Int. 114, 77-86. https://doi.org/10.1016/J.ENVINT.2018.02.014

Berntzon, L., Ronnevi, L.O., Bergman, B., Eriksson, J., 2015. Detection of BMAA in the human central nervous system. Neuroscience 292, 137-147.

https://doi.org/10.1016/j.neuroscience.2015.02.032

Berry, J.P., Gantar, M., Gibbs, P.D.L., Schmale, M.C., 2007. The zebrafish (Danio rerio) embryo as a model system for identification and characterization of developmental toxins from marine and freshwater microalgae. Comp. Biochem. Physiol. C. Toxicol. Pharmacol. 145, 61-72.

https://doi.org/10.1016/j.cbpc.2006.07.011

Biro, P.A., 2012. Do rapid assays predict repeatability in labile (behavioural) traits? Anim. Behav. 83, 1295-1300. https://doi.org/10.1016/j.anbehav.2012.01.036

Biro, P.A., Stamps, J.A., 2015. Using repeatability to study physiological and behavioural traits: ignore time-related change at your peril. Anim. Behav. 105, 223-230. https://doi.org/https://doi.org/10.1016/j.anbehav.2015.04.008

Brand, L.E., Pablo, J., Compton, A., Hammerschlag, N., Mash, D.C., 2010. Cyanobacterial blooms and the occurrence of the neurotoxin, beta-N-methylamino-l-alanine (BMAA), in South Florida aquatic food webs. Harmful Algae 9, 620-635. https://doi.org/10.1016/j.hal.2010.05.002

Brown, A.E.X., de Bivort, B., 2018. Ethology as a physical science. Nat. Phys. 14, 653-657. https://doi.org/10.1038/s41567-018-0093-0 
Burns, J.G., 2008. The validity of three tests of temperament in guppies (Poecilia reticulata). J. Comp. Psychol. 122, 344-356. https://doi.org/10.1037/0735-7036.122.4.344

Bustin, S.A., Benes, V., Garson, J.A., Hellemans, J., Huggett, J., Kubista, M., Mueller, R., Nolan, T., Pfaffl, M.W., Shipley, G.L., Vandesompele, J., Wittwer, C.T., 2009. The MIQE Guidelines: Minimum Information for Publication of Quantitative Real-Time PCR Experiments. Clin. Chem. 55, 61122. https://doi.org/10.1373/clinchem.2008.112797

Caller, T., Henegan, P., Stommel, E., 2018. The potential role of BMAA in neurodegeneration. Neurotox. Res. 33, 222-226. https://doi.org/10.1007/s12640-017-9752-7

Carion, A., Hétru, J., Markey, A., Suarez-Ulloa, V., Frédéric, S., 2018. Behavioral effects of the neurotoxin $\mathrm{B}-\mathrm{N}$-methylamino-L-alanine on the mangrove rivulus (Kryptolebias marmoratus) larvae. J. Xenobiotics 8. https://doi.org/10.4081/xeno.2018.7820

Carlin, R.K., Grab, D.J., Siekevitz, P., 1981. Function of calmodulin in postsynaptic densities III. Calmodulin-binding proteins of the postsynaptic density. J. Cell Biol. 89, 449-455. https://doi.org/http://jcb.rupress.org/content/89/3/449

Cases, O., Seif, I., Grimsby, J., Gaspar, P., Chen, K., Pournin, S., Müller, U., Aguet, M., Babinet, C., Shih, J.C., Maeyer, E. De, 1995. Aggressive behavior and altered amounts of brain serotonin and norepinephrine in mice lacking MAOA. Science (80-. ). 268, 1763-6.

Chernoff, N., Hill, D.J., Diggs, D.L., Faison, B.D., Francis, B.M., Lang, J.R., Larue, M.M., Le, T.-T., Loftin, K.A., Lugo, J.N., Schmid, J.E., Winnik, W.M., 2017. A critical review of the postulated role of the non-essential amino acid, $\beta$-N-methylamino-L-alanine, in neurodegenerative disease in humans. J. Toxicol. Environ. Heal. Part B 20, 183-229. https://doi.org/10.1080/10937404.2017.1297592

Chiu, A.S., Gehringer, M.M., Welch, J.H., Neilan, B.A., 2011. Does $\alpha$-amino- $\beta$-methylaminopropionic acid (BMAA) Ppay a role in neurodegeneration? Int. J. Environ. Res. Public Health 8, 3728-46. https://doi.org/10.3390/ijerph8093728

Churn, S.B., Limbrick, D., Sombati, S., DeLorenzo, R.J., 1995. Excitotoxic activation of the NMDA receptor results in inhibition of calcium/calmodulin kinase II activity in cultured hippocampal neurons. J. Neurosci. 15, 3200-14. https://doi.org/10.1523/JNEUROSCI.15-04-03200.1995

Cole, K.S., Noakes, D.L.G., 1997. Gonadal development and sexual allocation in mangrove killifish, Rivulus marmoratus (Pisces: Atherinomorpha). Copeia 596-600. https://doi.org/10.2307/1447566

Costa, W.J.E.M., 2011. Identity of Rivulus ocellatus and a new name for a hermaphroditic species of Kryptolebias from south-eastern Brazil (Cyprinodontiformes: Rivulidae). Ichthyol. Explor. Freshwaters 22, 185-192.

Cox, P.A., Banack, S.A., Murch, S.J., Rasmussen, U., Tien, G., Bidigare, R.R., Metcalf, J.S., Morrison, L.F., Codd, G.A., Bergman, B., 2005. Diverse taxa of cyanobacteria produce beta-N-methylamino-Lalanine, a neurotoxic amino acid. Proc. Natl. Acad. Sci. U. S. A. 102, 5074-8. https://doi.org/10.1073/pnas.0501526102

Cox, P.A., Davis, D.A., Mash, D.C., Metcalf, J.S., Banack, S.A., 2016a. Do vervets and macaques respond 
differently to BMAA? Neurotoxicology 57, 310-311.

https://doi.org/10.1016/J.NEUR0.2016.04.017

Cox, P.A., Davis, D.A., Mash, D.C., Metcalf, J.S., Banack, S.A., 2016b. Dietary exposure to an environmental toxin triggers neurofibrillary tangles and amyloid deposits in the brain. Proc. R. Soc. B Biol. Sci. 283, 20152397. https://doi.org/10.1098/rspb.2015.2397

Cox, P.A., Kostrzewa, R.M., Guillemin, G.J., 2018. BMAA and neurodegenerative illness. Neurotox Res 33, 178-83. https://doi.org/10.1007/s12640-017-9753-6

Cruz-Aguado, R., Winkler, D., Shaw, C.A., 2006. Lack of behavioral and neuropathological effects of dietary $\beta$-methylamino-l-alanine (BMAA) in mice. Pharmacol. Biochem. Behav. 84, 294-299. https://doi.org/10.1016/J.PBB.2006.05.012

Dai, X., Zhang, W., Zhuo, Z., He, J., Yin, Z., 2015. Neuroendocrine regulation of somatic growth in fishes. Sci. China Life Sci. 58, 137-147. https://doi.org/10.1007/s11427-015-4805-8

Denoël, M., D’Hooghe, B., Ficetola, G.F., Brasseur, C., De Pauw, E., Thomé, J.-P., Kestemont, P., 2012. Using sets of behavioral biomarkers to assess short-term effects of pesticide: a study case with endosulfan on frog tadpoles. Ecotoxicology 21, 1240-1250. https://doi.org/10.1007/s10646012-0878-3

Denoël, M., Libon, S., Kestemont, P., Brasseur, C., Focant, J.-F., De Pauw, E., 2013. Effects of a sublethal pesticide exposure on locomotor behavior: a video-tracking analysis in larval amphibians. Chemosphere 90, 945-51. https://doi.org/10.1016/j.chemosphere.2012.06.037

Earley, R.L., Hanninen, A.F., Fuller, A., Garcia, M.J., Lee, E. a, 2012. Phenotypic plasticity and integration in the mangrove rivulus (Kryptolebias marmoratus): a prospectus. Integr. Comp. Biol. 52, 814-27. https://doi.org/10.1093/icb/ics118

Earley, R.L., Hsu, Y., Wolf, L.L., 2000. The use of standard aggression testing methods to predict combat behaviour and contest outcome in Rivulus marmoratus dyads "(Teleostei: Cyprinodontidae). Ethology 106, 743-761. https://doi.org/https://doi.org/10.1046/j.14390310.2000.00586.x

Esterhuizen-Londt, M., Downing, T., 2011. Solid phase extraction of $\beta$-N-methylamino-L-alanine (BMAA) from South African water supplies. Water 37, 523-528. https://doi.org/10.4314/wsa.v37i4.10

Faassen, E.J., 2014. Presence of the neurotoxin BMAA in aquatic ecosystems: What do we really know? Toxins (Basel). 6, 1109-38. https://doi.org/10.3390/toxins6031109

Faassen, E.J., García-Altares, M., Mendes e Mello, M., Lürling, M., 2015. Trans generational effects of the neurotoxin BMAA on the aquatic grazer Daphnia magna. Aquat. Toxicol. 168, 98-107. https://doi.org/10.1016/J.AQUATOX.2015.09.018

Fellous, A., Anne-sophie, T.L.M.L., Ryan, V., Frederic, L.E., 2018. DNA methylation in adults and during development of the self- fertilizing mangrove rivulus , Kryptolebias marmoratus. Ecol. Evol. 1-18. https://doi.org/10.1002/ece3.4141

Frøyset, A.K., Khan, E.A., Fladmark, K.E., 2016. Quantitative proteomics analysis of zebrafish exposed to sub-lethal dosages of $\beta$-methyl-amino-L-alanine (BMAA). Sci. Rep. 6. 
https://doi.org/10.1038/srep29631

Garamszegi, L.Z., Mueller, J.C., Markó, G., Szász, E., Zsebok, S., Herczeg, G., Eens, M., Török, J., Aszl, L., Garamszegi, Z., Mueller, J.C., Abor Mark, G., Sz Asz, E., Ok, Z., Abor Herczeg, G., Eens, M., Anos, \& J., Or€ Ok, T., Garamszegi, L.Z., Mueller, J.C., Markó, G., Szász, E., Zsebők, S., Herczeg, G., Eens, M., Török, J., Zsebok, S., Herczeg, G., Eens, M., Török, J., 2014. The relationship between DRD4 polymorphisms and phenotypic correlations of behaviors in the collared flycatcher. Ecol. Evol. 4, 1466-1479. https://doi.org/10.1002/ece3.1041

Garcia, M.J., Ferro, J.M., Mattox, T., Kopelic, S., Marson, K., Jones, R., Svendsen, J.C., Earley, R.L., 2016. Phenotypic differences between the sexes in the sexually plastic mangrove rivulus fish (Kryptolebias marmoratus). J. Exp. Biol. 219, 988-997. https://doi.org/10.1242/jeb.124040

Glover, W.B., Mash, D.C., Murch, S.J., 2014. The natural non-protein amino acid N- $\beta$-methylamino-lalanine (BMAA) is incorporated into protein during synthesis. Amino Acids 46, 2553-2559. https://doi.org/10.1007/s00726-014-1812-1

Groh, K.J., Carvalho, R.N., Chipman, J.K., Denslow, N.D., Halder, M., Murphy, C.A., Roelofs, D., Rolaki, A., Schirmer, K., Watanabe, K.H., 2015. Development and application of the adverse outcome pathway framework for understanding and predicting chronic toxicity: II. A focus on growth impairment in fish. Chemosphere 120, 778-792. https://doi.org/10.1016/J.CHEMOSPHERE.2014.10.006

Haining, R.L., Achat-Mendes, C., 2017. Neuromelanin, one of the most overlooked molecules in modern medicine, is not a spectator. Neural Regen Res 12, 372-375. https://doi.org/10.1016/j.pneurobio.2015.09.012

Halliwell, B., 2007. Inflammation biochemistry of oxidative stress. Biochem. Soc. Trans. 35, 11471150. https://doi.org/10.1042/BST0351147

Harrington, R.W., 1961. Oviparous hermaphroditic fish with internal self-fertilization. Science (80-. ). 134, 1749-1750. https://doi.org/10.1126/science.134.3492.1749

Hellemans, J., Mortier, G., De Paepe, A., Speleman, F., Vandesompele, J., 2007. qBase relative quantification framework and software for management and automated analysis of real-time quantitative PCR data. Genome Biol. 8, 1901-1914. https://doi.org/10.1186/gb-2007-8-2-r19

Hellou, J., 2011. Behavioural ecotoxicology, an "early warning" signal to assess environmental quality. Environ. Sci. Pollut. Res. 18, 1-11. https://doi.org/10.1007/s11356-010-0367-2

Horzmann, K., Freeman, J., 2016. Zebrafish get connected: Investigating neurotransmission targets and alterations in chemical toxicity. Toxics 4, 19. https://doi.org/10.3390/toxics4030019

Htway, S.-M., Sein, M.-T., Nohara, K., Win-Shwe, T.-T., 2019. Effects of developmental arsenic exposure on the social behavior and related gene expression in $\mathrm{C} 3 \mathrm{H}$ adult male mice. Int. J. Environ. Res. Public Health 16. https://doi.org/10.3390/IJERPH16020174

Isik, A.T., 2010. Late onset Alzheimer's disease in older people. Clin. Interv. Aging 5, 307-11. https://doi.org/10.2147/CIA.S11718 
James, W.R., Styga, J.M., White, S., Marson, K.M., Earley, R.L., 2018. Phenotypically plastic responses to predation threat in the mangrove rivulus fish (Kryptolebias marmoratus): behavior and morphology. Evol. Ecol. 32, 453-468. https://doi.org/10.1007/s10682-018-9952-5

Jedrychowski, W.A., Perera, F.P., Camann, D., Spengler, J., Butscher, M., Mroz, E., Majewska, R., Flak, E., Jacek, R., Sowa, A., 2015. Prenatal exposure to polycyclic aromatic hydrocarbons and cognitive dysfunction in children. Environ. Sci. Pollut. Res. 22, 3631-3639. https://doi.org/10.1007/s11356-014-3627-8

Karamyan, V.T., Speth, R.C., 2008. Animal models of BMAA neurotoxicity: A critical review. Life Sci. 82, 233-46. https://doi.org/10.1016/J.LFS.2007.11.020

Karlsson, O., Lindquist, N.G., Brittebo, E.B., Roman, E., 2009a. Selective brain uptake and behavioral effects of the cyanobacterial toxin BMAA ( $\beta$-N-methylamino-L-alanine) following neonatal administration to rodents. Toxicol. Sci. 109, 286-295. https://doi.org/10.1093/toxsci/kfp062

Karlsson, O., Roman, E., Brittebo, E.B., 2009b. Long-term cognitive impairments in adult rats treated neonatally with $\beta$-N-methylamino-L-alanine. Toxicol. Sci. 112, 185-195.

https://doi.org/10.1093/toxsci/kfp196

Kelley, J.L., Yee, M.-C., Brown, A.P., Richardson, R.R., Tatarenkov, A., Lee, C.C., Harkins, T.T., Bustamante, C.D., Earley, R.L., 2016. The genome of the self-fertilizing mangrove rivulus fish, Kryptolebias marmoratus : a model for studying phenotypic plasticity and adaptations to extreme environments. Genome Biol. Evol. evw145. https://doi.org/10.1093/gbe/evw145

Kozul-Horvath, C.D., Zandbergen, F., Jackson, B.P., Enelow, R.I., Hamilton, J.W., 2012. Effects of lowdose drinking water arsenic on mouse fetal and postnatal growth and development. PLoS One 7, e38249. https://doi.org/10.1371/journal.pone.0038249

Lage, S., Ström, L., Godhe, A., Rydberg, S., 2018. Kinetics of $\beta$-N-methylamino-L-alanine (BMAA) and 2, 4-diaminobutyric acid (DAB) production by diatoms: the effect of nitrogen. Eur. J. Phycol. 54, 115-125. https://doi.org/10.1080/09670262.2018.1508755

Laugeray, A., Oummadi, A., Jourdain, C., Feat, J., Meyer-Dilhet, G., Menuet, A., Plé, K., Gay, M., Routier, S., Mortaud, S., Guillemin, G.J., 2018. Perinatal exposure to the cyanotoxin $\beta$-N-methylamino-lalanine (BMAA) results in long-lasting behavioral changes in offspring-potential involvement of DNA damage and oxidative stress. Neurotox. Res. 33, 87-112.

https://doi.org/10.1007/s12640-017-9802-1

Lewerenz, J., Maher, P., 2015. Chronic glutamate toxicity in neurodegenerative diseases-What is the evidence? Front. Neurosci. 9, 469. https://doi.org/10.3389/fnins.2015.00469

Lobner, D., Piana, P.M.T., Salous, A.K., Peoples, R.W., 2007. $\beta$-N-methylamino-l-alanine enhances neurotoxicity through multiple mechanisms. Neurobiol. Dis. 25, 360-366. https://doi.org/10.1016/j.nbd.2006.10.002

Mackiewicz, M., Tatarenkov, A., Turner, B.J., Avise, J.C., 2006. A mixed-mating strategy in a hermaphroditic vertebrate. Proc. R. Soc. 273, 2449-52.

https://doi.org/10.1098/rspb.2006.3594 
Mason, L.H., Harp, J.P., Han, D.Y., 2014. Pb neurotoxicity: neuropsychological effects of lead toxicity. Biomed Res. Int. 1-8. https://doi.org/10.1155/2014/840547

Montine, T.J., Li, K., Perl, D.P., Galasko, D., 2005. Lack of $\beta$-methylamino-l-alanine in brain from controls, AD, or Chamorros. Neurology 65. https://doi.org/10.1212/01.wnl.0000174523.62022.52

Myhre, O., Eide, D.M., Kleiven, S., Utkilen, H.C., Hofer, T., 2018. Repeated five-day administration of L-BMAA, microcystin-LR, or as mixture, in adult C57BL/6 mice - lack of adverse cognitive effects. Sci. Rep. 8, 2308. https://doi.org/10.1038/s41598-018-20327-y

Newman, T.K., Syagailo, Y. V., Barr, C.S., Wendland, J.R., Champoux, M., Graessle, M., Suomi, S.J., Higley, J.D., Lesch, K.-P., 2005. Monoamine oxidase A gene promoter variation and rearing experience influences aggressive behavior in rhesus monkeys. Biol. Psychiatry 57, 167-172. https://doi.org/10.1016/J.BIOPSYCH.2004.10.012

Nunn, P.B., 2017. 50 years of research on $\alpha$-amino- $\beta$-methylaminopropionic acid ( $\beta$ methylaminoalanine). Phytochemistry 144, 271-81.

https://doi.org/10.1016/J.PHYTOCHEM.2017.10.002

O'Neil, J.M., Davis, T.W., Burford, M.A., Gobler, C.J., 2012. The rise of harmful cyanobacteria blooms: The potential roles of eutrophication and climate change. Harmful Algae 14, 313-334. https://doi.org/10.1016/J.HAL.2011.10.027

Pagano, G., Ferrara, N., Brooks, D.J., Pavese, N., 2016. Age at onset and Parkinson disease phenotype. Neurology 86, 1400-1407. https://doi.org/10.1212/WNL.0000000000002461

Pérez-Sánchez, J., Simó-Mirabet, P., Naya-Català, F., Martos-Sitcha, J.A., Perera, E., Bermejo-Nogales, A., Benedito-Palos, L., Calduch-Giner, J.A., 2018. Somatotropic axis regulation unravels the differential effects of nutritional and environmental factors in growth performance of marine farmed fishes. Front. Endocrinol. (Lausanne). 9, 687. https://doi.org/10.3389/fendo.2018.00687

Pinzón-Olejua, A., Welte, C., Abdesselem, H., Málaga-Trillo, E., Stuermer, C.A.O., 2014. Essential roles of zebrafish rtn4/Nogo paralogues in embryonic development. Neural Dev. 9. https://doi.org/10.1186/1749-8104-9-8

Popova, A.A., Rasmussen, U., Semashko, T.A., Govorun, V.M., Koksharova, O.A., 2018. Stress effects of cyanotoxin $\beta$-methylamino-L-alanine (BMAA) on cyanobacterial heterocyst formation and functionality. Environ. Microbiol. Rep. 10, 369-377. https://doi.org/10.1111/17582229.12647

Powers, S., Kwok, S., Lovejoy, E., Lavin, T., Sher, R., 2017. Embryonic exposure to the environmental neurotoxin BMAA negatively impacts early neuronal development and progression of neurodegeneration in the Sod1-G93R zebrafish model of amyotrophic lateral sclerosis. Toxicol. Sci. 157, kfx020. https://doi.org/10.1093/toxsci/kfx020

Purdie, Esme L., Metcalf, J.S., Kashmiri, S., Codd, G.A., 2009. Toxicity of the cyanobacterial neurotoxin $\beta$-N-methylamino-L-alanine to three aquatic animal species. Amyotroph. Lateral Scler. 10, 67-70. https://doi.org/10.3109/17482960903273551 
Purdie, E L, Samsudin, S., Eddy, F.B., Codd, G.A., 2009. Effects of the cyanobacterial neurotoxin $\beta$-Nmethylamino-L-alanine on the early-life stage development of zebrafish (Danio rerio). Aquat. Toxicol. 95, 279-284. https://doi.org/10.1016/j.aquatox.2009.02.009

Rao, S.D., Banack, S.A., Cox, P.A., Weiss, J.H., 2006. BMAA selectively injures motor neurons via AMPA/kainate receptor activation. Exp. Neurol. 201, 244-252. https://doi.org/10.1016/j.expneurol.2006.04.017

Rauk, A., 2018. $\beta$-N-methylamino-L-alanine (BMAA) not involved in Alzheimer's disease. J. Phys. Chem. 122, 4472-80.

Réale, D., Reader, S.M., Sol, D., McDougall, P.T., Dingemanse, N.J., 2007. Integrating animal temperament within ecology and evolution. Biol. Rev. Camb. Philos. Soc. 82, 291-318. https://doi.org/10.1111/j.1469-185X.2007.00010.x

Reiter, R.J., Manchester, L.C., Tan, D.-X., 2010. Neurotoxins: free radical mechanisms and melatonin protection. Curr. Neuropharmacol. 8, 194-210. https://doi.org/10.2174/157015910792246236

Roen, E.L., 2015. Bisphenol A exposure and behavioral problems among inner city children at 7-9 years of age. Env. Res. 142, 739-745. https://doi.org/10.1177/0333102415576222.Is

Salierno, J.D., 2005. Harmful algal bloom stressors alter behavior and brain activity in the killifish, Fundulus heteroclitus. University of Maryland.

Salim, S., 2017. Oxidative stress and the central nervous system. J. Pharmacol. Exp. Ther. 360, 201205. https://doi.org/10.1124/jpet.116.237503

Santiago, M., Matarredona, E.R., Machado, A., Cano, J., 2006. Acute perfusion of BMAA in the rat's striatum by in vivo microdialysis. Toxicol. Lett. 167, 34-39.

https://doi.org/10.1016/j.toxlet.2006.08.005

Scarsella, G.E., Gresham, J.D., Earley, R.L., 2018. Relationships between external sexually dimorphic characteristics and internal gonadal morphology in a sex changing fish. J. Zool. 305, 133-140. https://doi.org/doi:10.1111/jzo.12546

Scott, L., Downing, T., 2019. Dose-dependent adult neurodegeneration in a rat model after neonatal exposure to $\beta$-N-methylamino-L-alanine. Neurotox. Res. 35, 711-723. https://doi.org/10.1007/s12640-019-9996-5

Scott, L.L., Downing, T.G., 2017. A single neonatal exposure to BMAA in a rat model produces neuropathology consistent with neurodegenerative diseases. Toxins (Basel). 10, 18-23. https://doi.org/10.3390/toxins10010022

Sih, A., Stamps, J., Yang, L.H., McElreath, R., Ramenofsky, M., 2010. Behavior as a key component of integrative biology in a human-altered world. Integr. Comp. Biol. 50, 934-944. https://doi.org/10.1093/icb/icq148

Smith, V.H., 2003. Eutrophication of freshwater and coastal marine ecosystems a global problem. Environ. Sci. Pollut. Res. 10, 126-139. https://doi.org/10.1065/espr2002.12.142

Sneddon, L.U., Margareto, J., Cossins, A.R., 2005. The use of transcriptomics to address questions in 
behaviour: production of a suppression subtractive hybridisation library from dominance hierarchies of rainbow trout. Physiol. Biochem. Zool. 78, 695-705.

https://doi.org/10.1086/432141

Sneddon, L.U., Schmidt, R., Fang, Y., Cossins, A.R., 2011. Molecular correlates of social dominance: A novel role for ependymin in aggression. PLoS One 6, e18181.

https://doi.org/10.1371/journal.pone.0018181

Snyder, L.R., Cruz-Aguado, R., Sadilek, M., Galasko, D., Shaw, C.A., Montine, T.J., 2009. Lack of cerebral BMAA in human cerebral cortex. Neurology 72, 1360-1. https://doi.org/10.1212/WNL.0b013e3181a0fed1

Soto, C.G., Noakes, D.L.G., 1994. Coloration and gender in the hermaphroditic fish Rivulus marmoratus Poey (Teleostei: Rivulidae). ). Icthyol. Explor. Freshwaters 5, 79-90.

Stamps, J., Groothuis, T.G.G., 2010. The development of animal personality: relevance, concepts and perspectives. Biol. Rev. Camb. Philos. Soc. 85, 301-25. https://doi.org/10.1111/j.1469185X.2009.00103.x

Swulius, M.T., Waxham, M.N., 2008. Ca 2+ /Calmodulin-dependent Protein Kinases. Cell. Mol. Life Sci. 65, 2637-2657. https://doi.org/10.1007/s00018-008-8086-2

Tatarenkov, A., Lima, S.M.Q., Taylor, D.S., Avise, J.C., 2009. Long-term retention of self-fertilization in a fish clade. Proc. Natl. Acad. Sci. U. S. A. 106, 14456-9. https://doi.org/10.1073/pnas.0907852106

Taylor, D.S., 2012. Twenty-four years in the mud: What have we learned about the natural history and ecology of the mangrove rivulus, Kryptolebias marmoratus? Integr. Comp. Biol. 52, ics062-. https://doi.org/10.1093/icb/ics062

Thomson, J.S., Watts, P.C., Pottinger, T.G., Sneddon, L.U., 2012. Plasticity of boldness in rainbow trout, Oncorhynchus mykiss: do hunger and predation influence risk-taking behaviour? Horm. Behav. 61, 750-757. https://doi.org/0.1016/j.yhbeh.2012.03.014

van Onselen, R., Venables, L., van de Venter, M., Downing, T.G., 2018. $\beta$-N-methylamino-L-alanine toxicity in PC12: excitotoxicity vs. misincorporation. Neurotox. Res. 33, 15-23. https://doi.org/10.1007/s12640-017-9743-8

Vega, A., Bell, E.A., 1967. $\alpha$-Amino- $\beta$-methylaminopropionic acid, a new amino acid from seeds of Cycas circinalis. Phytochemistry 6, 759-62. https://doi.org/10.1016/S0031-9422(00)86018-5

Viberg, H., 2009. Exposure to polybrominated diphenyl Ethers 203 and 206 during the neonatal brain growth spurt affects proteins important for normal neurodevelopment in mice. Toxicol. Sci. 109, 306-311. https://doi.org/10.1093/toxsci/kfp074

Voisin, A.-S., Fellous, A., Earley, R.L., Silvestre, F., 2016. Delayed impacts of developmental exposure to 17- $\alpha$-ethinylestradiol in the self-fertilizing fish Kryptolebias marmoratus. Aquat. Toxicol. 180, 247-257. https://doi.org/10.1016/j.aquatox.2016.10.003

Voisin, A.-S., Kültz, D., Silvestre, F., 2018. Early-life exposure to the endocrine disruptor 17- $\alpha$ ethinylestradiol induces delayed effects in adult brain, liver and ovotestis proteomes of a selffertilizing fish. J. Proteomics 194, 112-124. https://doi.org/10.1016/J.JPROT.2018.12.008 
Yegambaram, M., Manivannan, B., Beach, T.G., Halden, R.U., 2015. Role of environmental contaminants in the etiology of Alzheimer's disease: a review. Curr. Alzheimer Res. 12, 11646. https://doi.org/10.2174/1567205012666150204121719

Ziegler, C., Richter, J., Mahr, M., Gajewska, A., Schiele, M.A., Gehrmann, A., Schmidt, B., Lesch, K.-P., Lang, T., Helbig-Lang, S., Pauli, P., Kircher, T., Reif, A., Rief, W., Vossbeck-Elsebusch, A.N., Arolt, V., Wittchen, H.-U., Hamm, A.O., Deckert, J., Domschke, K., 2016. MAOA gene hypomethylation in panic disorder-reversibility of an epigenetic risk pattern by psychotherapy. Transl. Psychiatry 6, e773. https://doi.org/10.1038/tp.2016.41

Zucca, F.A., Basso, E., Cupaioli, F.A., Ferrari, E., Sulzer, D., Casella, L., Zecca, L., 2014. Neuromelanin of the human substantia nigra: an update. Neurotox. Res. 25, 13-23. https://doi.org/10.1007/s12640-013-9435-y

Appendix A. Supplementary data

Received 5 June 2019, Revised 16 April 2020, Accepted 21 April 2020, Available online 5 May 2020. 